\title{
Operando desde la forma: un procedimiento para la valoración de la vivienda colectiva
}

\author{
Operating based on form: A procedure for the valuation of collective housing \\ Operando a partir da forma: um procedimento para avaliar a moradia coletiva
}

\author{
Julián Camilo Valderrama-Vidal \\ Universidad Piloto de Colombia, Bogotá (Colombia) \\ Facultad de Arquitectura y Artes
}

\section{Introducción}

\section{Calidad a partir de la forma}

Arquitecto, Universidad Piloto de Colombia, Bogotá (Colombia).

Arquitecto en CFC\&A Construcciones.

Interés académico centrado en instrumentos de análisis de composiciones arquitectónicas.

(D) http://orcid.org/0000-0002 0930-272।

jvald44@gmail.com

\section{Resumen}

La investigación Cinco proyectos de vivienda colectiva: un ensayo sobre la calidad arquitectónica desde la forma, tiene como objetivo precisar el concepto de calidad para la vivienda colectiva en términos de formalidad, pues, las usuales apreciaciones del término calidad (una reunión de estimaciones subjetivas o un listado de chequeo), desvirtúan el papel de la arquitectura dentro del diseño de la vivienda. Mediante procesos de análisis formal y síntesis en matrices de información se obtiene como resultado otra manera de entender la calidad arquitectónica a partir de la discusión entre cosa, utensilio y obra de arte. Asimismo, partiendo de la comparación entre el conjunto Residencias El Parque (Rogelio Salmona) y otros proyectos de vivienda colectiva como Robin Hood Garden (Peter y Alison Smithson), Inmuebles Villa (Le Corbusier), 88 viviendas en Carabanchel (Nicolás Maruri y ACM Arquitectos), y la Unidad Habitacional de Marsella (Le Corbusier), se identificaron las operaciones de su conformación, y se aportó una manera diferente de juzgar la vivienda colectiva, pues la operación formal no solo se emplea como un medio compositivo, sino también para la creación de paisaje.

Palabras clave: arquitectura colombiana; composición arquitectónica; diseño de edificios de viviendas; investigación proyectual; paisaje urbano.

\section{Abstract}

This article presents the results of the research Five projects of collective housing: An essay about architectural quality based on form, which aimed to specify the concept of quality for collective housing in terms of formality, given that the usual understandings of the term "quality" (a set of subjective estimates or a check list) distort the role of architecture in the design of housing units. This research proposes a different way to understand architectural quality based on a discussion of the concepts "thing," "tool," and "artwork." Similarly, it compares its study object, the towers of Residencias El Parque designed by Rogelio Salmona, with other collective housing projects to identify their respective configurative operations, which offered a different way to judge collective housing, since formal operation is not only considered as a compositional means, but it is also used for the creation of landscape.

Keywords: Colombian architecture; architectural composition; residential building design; project research; urban landscape.

\section{Resumo}

A pesquisa "Cinco projetos de moradia coletiva: um ensaio sobre a qualidade arquitetônica a partir da forma" tem como objetivo precisar o conceito de qualidade para a moradia coletiva em termos de formalidade, uma vez que as usuais apreciações do termo "qualidade" (uma reunião de estimativas subjetivas ou uma lista de checagem) desvirtuam o papel da arquitetura dentro do desenho da moradia. Mediante processos de análise formal e síntese em matrizes de informação, é obtida como resultado outra maneira de entender a qualidade arquitetônica a partir da discussão entre coisa, utensílio e obra de arte. Além disso, partindo da comparação entre o conjunto residencial El Parque (Rogelio Salmona) e outros projetos de moradia coletiva como Robin Hood Garden (Peter e Alison Smithson), Inmuebles Villa (Le Corbusier), 88 moradias em Carabanchel (Nicolás Maruri e ACM Arquitectos) e a Unidad Habitacional de Marsella (Le Corbusier), identificaram-se as operações de sua conformação e contribuiu-se com uma maneira diferente de avaliar a moradia coletiva, pois a operação formal não somente é empregada como um meio compositivo, mas também para criar paisagem.

Palavras-chave: arquitetura colombiana; composição arquitetônica; desenho de edifícios residenciais; pesquisa projetual; paisagem urbana.

Cinco proyectos de vivienda colectiva: un ensayo sobre la calidad arquitectónica desde la forma fue un trabajo de investigación defendido en la Facultad de Arquitectura y Artes de la Universidad Piloto de Colombia como proyecto de grado. Esta investigación nace del análisis del proyecto Residencias El Parque, del arquitecto Rogelio Salmona, y sus diversos juicios como una obra destacable; estos juicios llevan a preguntarse por qué razones suele elogiarse sobremanera, más allá de las interpretaciones personales o constructivas, y cómo estas aseveraciones no son una cuestión atendida con más profundidad. Seguidamente, se corrobora si lo analizado en Salmona se repite en otros casos de estudio como el Robin Hood Garden de Alison y Peter Smithson (Londres, 1972), Caravanchel 17 de Nicolás Maruri y ACM Arquitectos (Madrid, 2009), los Inmuebles Villa (París, 1922) y la Unidad Habitacional de Marsella (1952) de Le Corbusier; y se conduce a la comprensión del objetivo que esta investigación presenta como la definición de un concepto de calidad arquitectónica.

El estudio inicia observando cómo, hoy por hoy, los parámetros comerciales son la base del surgimiento de viviendas, al atender el valor de un predio o su ubicación estratégica, dejando de lado el aspecto compositivo. Y como también lo hace su enfoque normativo que no contempla ejercicios formales como criterio de diseño, pero sí resultados utilitarios y físicos que predeterminan su constitución: "implican que una modificación sustancial en una vivienda debe ajustarse a la norma" (Monteys, 2012, p. 23). La planeación de un proyecto multifamiliar, y la predisposición al facilismo formal, se explican a partir de este enfoque cuantitativo. De igual forma, paralelo a este aspecto objetivo se presenta la concertación de las virtudes de la vivienda, al cuestionar la perspectiva del usuario que, sin querer subestimarse, indaga por la calidad de manera heterónoma a la disciplina arquitectónica, pues parte de la satisfacción por el uso de los espacios residenciales como mecanismo de construcción, separado de valoraciones formales. Este inconveniente preliminar muestra que el carácter y la calidad de la vivienda se estiman en tanto grupo de cuantías y en pautas dictadas desde la subjetividad de los usuarios, lo que hace difícil su valoración desde la disciplina. Lo anterior lleva a preguntarse, entonces, cómo establecer la calidad en la vivienda colectiva desde la arquitectura. 
Ahora, si se ignora el aspecto formal al momento de establecer el carácter de la vivienda, habría entonces que definir algunas pautas para hablar sobre formalidad y su correspondencia con la vivienda, por lo cual este trabajo toma como punto de partida el caso de la edificación de rascacielos y el razonamiento trabajado en Delirious New York (Koolhaas, 2004). Este texto aborda el surgimiento de las grandes edificaciones en la isla de Manhattan, que expone como volumetrías puras y de desproporcionada geometría. Cuerpos que similar a los demás edificios de gran altura, presentan un punto de fractura en que se desprenden de cualquier expresión artística. Este desprendimiento de lenguajes para definir su carácter expone una dificultad en términos de forma.

Al extenderse más, Koolhaas añade que este exceso en las edificaciones no solo pasa por alto el uso de gestos arquitectónicos, sino que además genera otro problema desfavorable para su contexto como lo es la generación de grandes sombras. Un dilema que es atendido por la creación de una ordenanza para reducir su área a determinada altura y reducir sus sombras. Esta ordenanza, denominada Ley de Zonificación, no solo atendió las demandas de sol, vientos, etc., que el edificio requería, sino también se convirtió en una condicionante de diseño, no orientada a atender los aspectos formales y sus efectos en la edificación, pero sí los de asoleación, congestión y reducción de tránsito (Figura 1).

De acuerdo con esto, Hugh Ferris afirmaba:

La ley de Nueva York, formulada por un grupo de expertos técnicos, se basaba en consideraciones puramente prácticas [...], al limitar el volumen de un edificio, el número de ocupantes era limitado; menos personas necesitan acceso y salida; el tráfico en las calles adyacentes fue aclarado. [...] De hecho, cuando la ley fue aprobada por primera vez, los estándares arquitectónicos conservadores fueron arrojados a la confusión. En un punto tras otro, los diseñadores se vieron enfrentados a restricciones que imposibilitaban la erección de formas familiares (1929, p. 72) ${ }^{1}$

La concepción de este recurso, ante la desmesura emanada de la edificación, refleja una separación entre el edificio y cualquier postura formal, que aparta cualquier consideración o cualidad positiva desde la arquitectura. El empleo de este medio ante la gran volumetría del edificio, no solo indica un distanciamiento entre una valoración formal y el proyecto, sino que también aparta consideraciones positivas

\footnotetext{
1 "The New York law, formulated by a group of technical experts was based on purely practical considerations [...] by limiting the bulk of a building, the number of occupants was limited; fewer people required access and egress; traffic on adjoining streets was lightened. [...] As a matter of fact, when the law was first passed, conservative architectural standards were thrown into confusion. At point after point, designers found themselves faced by restrictions which made the erecting of familiar forms impossible" (traducción propia).
}

desde la disciplina pues, "su impacto es independiente de su calidad" (Koolhaas, 2011, p. 13).

Este no uso de gestos arquitectónicos también es abordado por Antonio Armesto en su texto Foro crítica: arquitectura y naturaleza (2008), quien le añade no solo una pérdida de carácter sino también una conducta heterónoma a la disciplina, pues reducir la edificación a solo una abstracción de su figura es caer en operaciones sintéticas y procedimientos mecánicos.

De acuerdo con esto, el proyecto La ciudad de la cultura de Galicia (1999), ubicado en Santiago de Compostela, y diseñado por Peter Eisenman, es el ejemplo de la postura de Armesto. Este proyecto se muestra como un corte realizado a la cima de una montaña que luego es sustituida por la implantación de un edificio que reconstruye la misma geografía. La exposición de un accidente geográfico, y no una función, releva a un segundo plano cualquier actividad compositiva: "la arquitectura se supedita, adopta una actitud servil, los edificios son comparsas de una farsa geográfica" (Armesto, 2008, p. 102).

Independientemente de los elementos dentro del proyecto, la figura de una montaña pretende adoptar diversos usos. La organización de elementos, o el diseño de partes del proyecto, no obedecen a una técnica o a un orden, sino a una delimitación espacial, con lo cual decae el papel de la arquitectura.

La siguiente base para exponer el problema con la formalidad habla sobre cómo el reflejo de una norma ejerce una carga a la estructura del sitio. Cómo esta puede acondicionar el sitio y el actuar de los usuarios inhibiendo no solo su dinamismo, sino también valoraciones de índole formal. Xavier Monteys, en su texto Rehabilitar en nueve episodios, explica cómo máximas normativas relegan la arquitectura a valores preceptivos, los cuales "implican que una modificación sustancial en una vivienda debe ajustarse a la norma" (Monteys, 2012, p. 23), en vez de limitarse a su acatamiento se pueden dar condiciones favorables para proyectar el hogar desde el interior hacia el exterior de la edificación. Una pieza que capta un fragmento del exterior, paralela a los parámetros normativos, cuyo propósito es generar algo más eminente para las viviendas.
(V) Figura 1. Consideraciones prácticas

Fuente: Valderrama (2014, p. 27). CC BY-NC-SA.
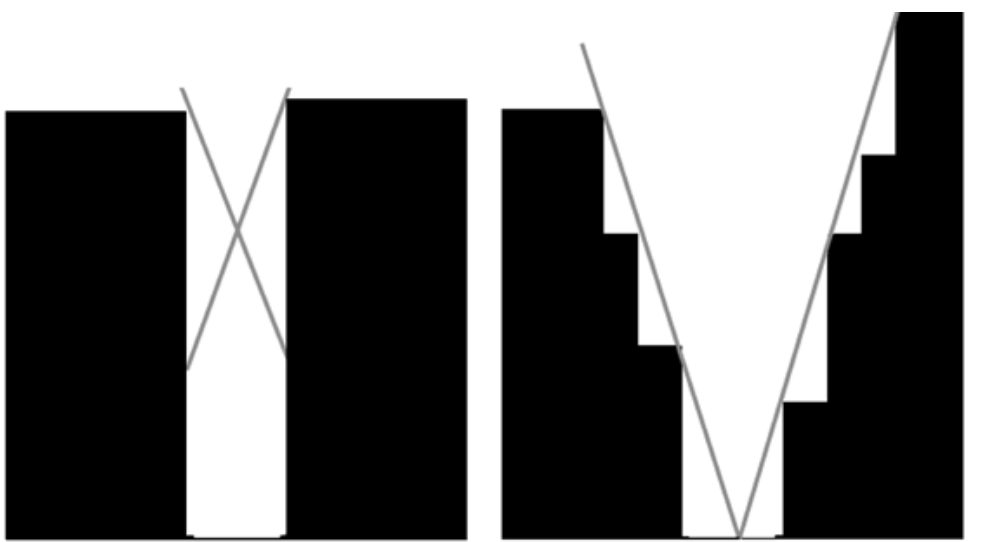
En el análisis ulterior de los proyectos se expone la estructura de investigación formal de Nicolás Maruri (2006) que, a diferencia de Rojas, se presenta como un complemento que resalta la idea de análisis de la forma arquitectónica. El recurso a estos dos autores, y el abordaje teórico previo sobre calidad, resaltan el carácter exploratorio de esta investigación, pues propone un nuevo marco de consulta para la concertación del término en cuestión.

En ese sentido, el propósito de la investigación parte de la formalidad concebida desde la tradición de la disciplina arquitectónica, inscribiendo esta disertación en la línea de investigación "Proyecto: Teorías, métodos y prácticas", de la Universidad Piloto de Colombia. Tres segmentos que enmarcan el objetivo de esta exploración de precisar un concepto de calidad para la vivienda colectiva en términos formales.

\section{Resultados}

La inquietud de esta investigación alrededor de la calidad en la vivienda colectiva en particular, y cómo es entendida en la arquitectura en general, proviene de una afirmación de la arquitecta Silvia Arango al juzgar el proyecto Residencias El Parque con una "contundencia inequívoca de la calidad" (1989, p. 247). Dicha afirmación, que a simple vista no se explicaba técnica o estéticamente, llevó a realizar este trabajo con el objeto de responder cómo se puede valorar la calidad en la vivienda colectiva, pues el aporte de esta investigación, cual es precisar un concepto de calidad desde la arquitectura, se justifica al poner de manifiesto y de manera crítica la estimación de la disciplina a partir de proposiciones axiomáticas o estéticas, pues señala cómo la calidad en la vivienda es usualmente valorada mediante la satisfacción del usuario o desde algún indicador o parámetro en particular. Aproximaciones que explican la calidad de manera externa a la arquitectura, y que plantean la necesidad de recuperar su autonomía como disciplina.

\section{Conceptualización de la calidad}

Para llevar a cabo la primera parte, este trabajo se apoya en el texto "El origen de la obra de arte" (Heidegger, 2010), con la intención de exponer el desafío que representa concertar la definición de calidad en la vivienda colectiva, y así realizar posteriormente una comparación de dicho pensamiento con otras fuentes que abarcan el tema en la arquitectura.

\section{La arquitectura como cosa}

La alusión a Martin Heidegger se debe a que su pensamiento permite la apreciación de la calidad, para esta investigación, como técnica. Un concepto visto como un medio que condiciona nuestro proceso de adaptación a la naturaleza, y, asimismo, una perspectiva instrumental que vincula al hombre con todo aquello que lo rodea. Un medio que al valorar el concepto de calidad en este trabajo no pretende mostrarse como cosa, puesto que al hacerlo definiría la arquitectura como una reunión de propiedades cuyo único fin es la producción de sensaciones frente a un sujeto. En otras palabras, asumir la arquitectura como aquello alrededor de lo cual se agrupan las propiedades en que una persona usualmente ve las cosas (Heidegger, 2010): feo, bonito, grande, pequeño.

Valorar la arquitectura como cosa equivaldría a evaluar la calidad en un proyecto de vivienda a partir de la belleza y el agrado que este genere. O bien, desde otra perspectiva, a partir de su excentricidad o extravagancia. Por ejemplo, en el texto Calidad de la vivienda dirigida a los sectores de bajos ingresos en Bogotá (Tarchópulos y Ceballos, 2003) se afirma: "a partir de interrogar sujetos sobre la opinión acerca de una espacialidad en particular [...] es posible extraer información que permita establecer su calidad de manera confiable" (p. 34), lo que indica, en este caso, que la calidad se define sobre planos personales.

Esta interpretación de la arquitectura como cosa apela a las propiedades en que usualmente se ve un proyecto de arquitectura: un proyecto agraciado, extravagante, elegante, etc., representa el carácter cósico de la disciplina al reducirla a un conjunto de sensaciones que dependen del gusto y juicio del individuo, y que, de paso, subordina el ejercicio compositivo a la contingencia y la inspiración.

\section{La arquitectura como utensilio}

Ahora bien, si esta investigación explora el punto de vista subjetivo de esta técnica (arquitectura como cosa), también antepone un punto de vista objetivo. Heidegger afirma que cuando la cosa dispone de una combinación de forma y materia (materia con-formada), no solo permite al hombre hacer un empleo de la técnica, sino que la técnica pasa de tener un rasgo cósico a un rasgo útil (2010, p. 18).

Por su parte, Tarchópulos y Ceballos (2003) exponen que la calidad, además de establecerse desde el juicio del usuario, se debe definir a partir de parámetros que establezcan características espaciales y físicas para una vivienda. Por ejemplo, diseñar una casa siguiendo una serie de requerimientos a modo de lista de chequeo y cuyo obediente cumplimiento lleva por ende a tener calidad. Este punto de vista expone una arquitectura como utensilio, pues se levanta sobre un proceso mecánico que no produce o crea, sino más bien fuerza y almacena. La arquitectura como utensilio señala el carácter útil de la disciplina, y se observa como un medio para establecer valores, cálculos o instrucciones de diseño.

Estas dos opciones (cosa y utensilio), empleadas para representar la calidad, relegan la arquitectura a factores heterónomos a la disciplina. El primer caso incurre en una mayor dificultad para entender y valorar proyectos desde el ejercicio 
compositivo, pues su fundamento no es un juicio teórico ni práctico, sino contemplativo y subjetivo (Kant, 2011). Mientras el segundo caso reduce el número de posibilidades de composición, pues su naturaleza es la simulación de fórmulas que, una vez despejadas, son propuestas como generadoras de la formalidad en un proyecto (Rojas, 2011). El empleo de estas técnicas demuestra una dificultad para definir la calidad en la vivienda colectiva desde el quehacer arquitectónico, pues su proceder es externo al mismo quehacer. Por tal razón, esta investigación indaga por un medio que valore este concepto desde la disciplina misma, y cuestione las observaciones anteriormente hechas, debido a que no aclaran su forma de proceder o para reproducirse, y que hace necesario exponer para asegurar la autonomía arquitectónica.

Si bien los papeles como cosa y como utensilio de la arquitectura nos sitúan en la búsqueda de un concepto de calidad, no apelan a una recuperación de su autonomía ni a la concreción del concepto en cuestión. Pero, al mismo tiempo, son el punto donde puede hallarse otro sentido a la calidad que esta disertación propone como la obra de arte.

\section{La arquitectura como obra de arte}

En el texto "El origen de la obra de arte" (Heidegger, 2010) se da un ejemplo del papel del arte en la Antigüedad, y su rol en la arquitectura griega: el templo griego. Heidegger pregunta ¿por qué ha generado tanta admiración a lo largo del tiempo? o ¿qué es aquello que la destaca? En su respuesta, él expone el destino del arte, no como generador de goces artísticos o satisfacción en un usuario, sino como técnica que permite a los hombres su acercamiento a algo más eminente: el diálogo entre hombres y dioses. Esta observación de la técnica como obra de arte lleva a preguntar si esta investigación puede precisar un concepto de calidad para la arquitectura empleando dicho concepto. No obstante, si la arquitectura como cosa y la arquitectura como utensilio se basan en planos personales y valores ponderados, esta investigación debería precisar las razones sobre las cuales se basaría la arquitectura como obra de arte.

Luego de estas observaciones sobre la reflexión de Heidegger, esta investigación asume el término arquitectura como cosa, en tanto una entidad definida y desligada de atributos o indicadores. A su vez, asume por arquitectura como utensilio a modo de un aparato que resuelve variables y cantidades. Y luego se propone precisar en qué consiste la arquitectura como obra de arte.

Para ello, esta disertación realiza un análisis de la forma arquitectónica a varios casos de vivienda colectiva empezando por las Residencias El Parque, del arquitecto Rogelio Salmona (1970), obra escogida a partir del juicio que señala este proyecto como obra destacable, recordando la apreciación "contundencia inequívoca de la cali-

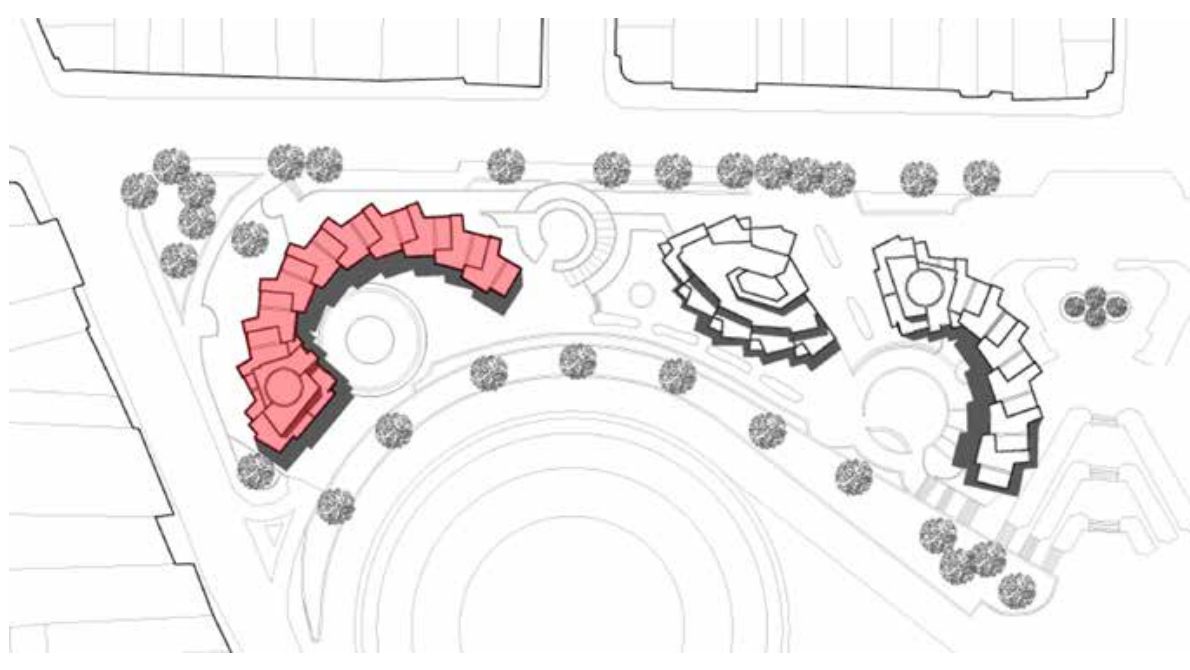

(A) Figura 3. Torre en consideración para estudio formal

Fuente: elaboración propia, 2014. Adaptado de Téllez (2013). CC BY-NC-SA.

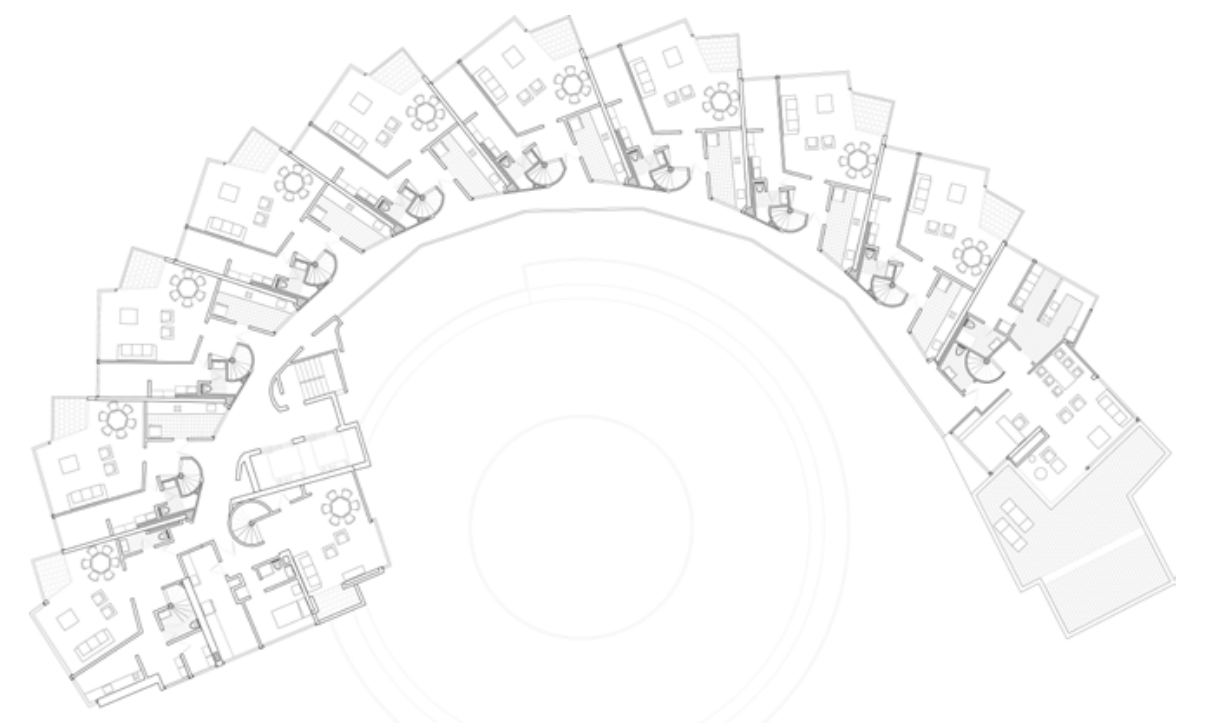

dad" (Arango, 1989, p. 247). Pero cabe preguntar, ¿calidad en las Residencias El Parque como cosa o calidad como utensilio?

Debido a esto, este segmento de la investigación se sirve de una hipótesis que enuncia que la deformación en las Residencias El Parque se da en atención al paisaje, puesto que su planteamiento es de orden formal (Rojas, comunicación personal, 10 de agosto de 2013).

\section{Análisis formal}

Las Residencias El Parque son un proyecto de vivienda colectiva localizado en el centro de Bogotá, comprendido por tres torres con un total de 294 apartamentos. Esta investigación aborda la hipótesis de Rojas como base preferencial, a partir de la cual se toma en consideración una de las torres (Figura 3), y se inicia el análisis hablando brevemente sobre el concepto de deformación, entendido como un cambio al aspecto de un cuerpo, mas no a la relación de sus partes (Rojas, 2012).

La hipótesis sobre la que se basa esta investigación sostiene que, actualmente, cada torre presenta un estado de deformación (Figura 4), el cual, si se invierte y racionaliza (Figuras 5 y 6), muestra la relación de sus conjuntos de vivienda en un sistema rectilíneo de crujías (Figuras 7 y 8).
(A) Figura 4. Estado actual de deformación

Fuente: elaboración propia, 2014. CC BY-NC-SA. 


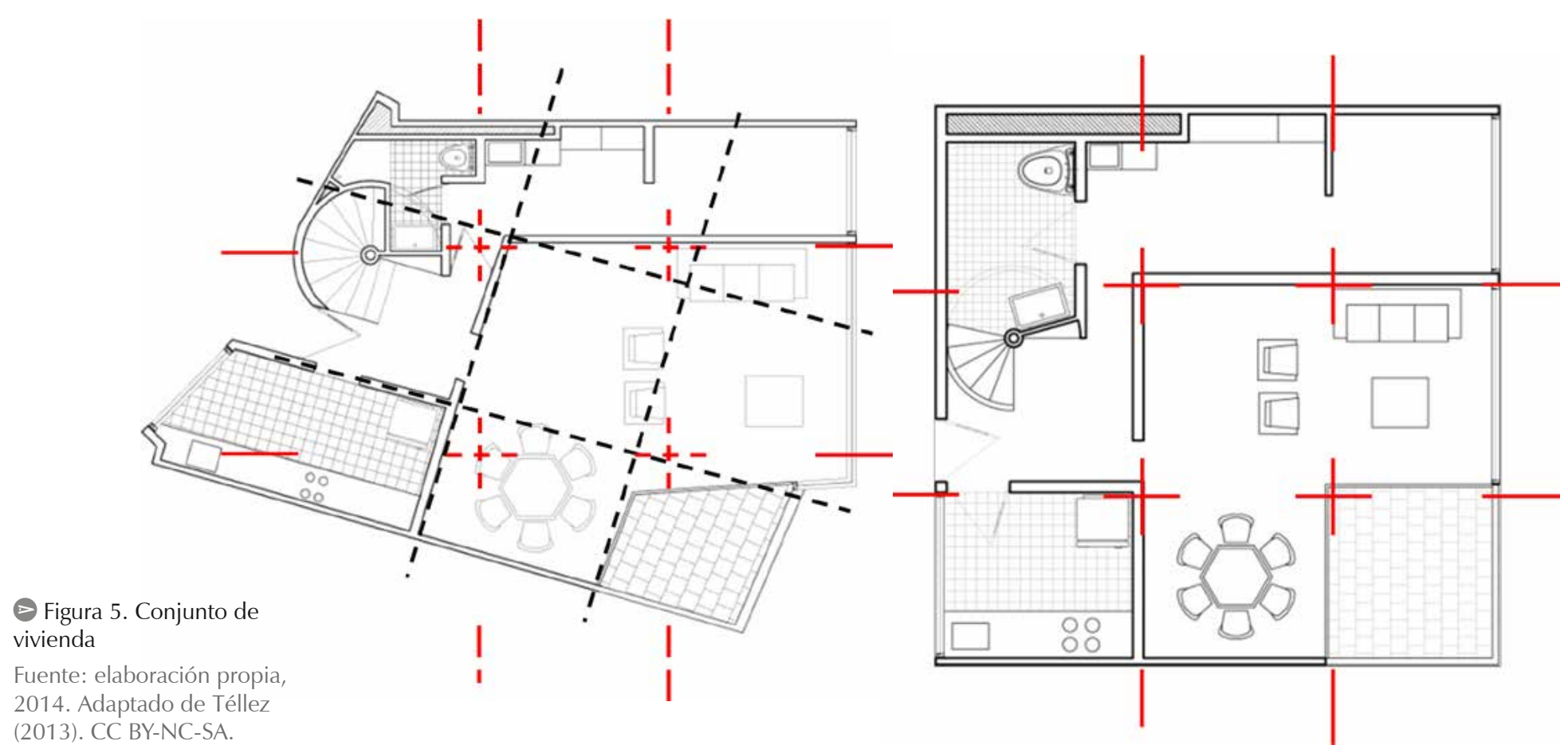

(2013). CC BY-NC-SA.

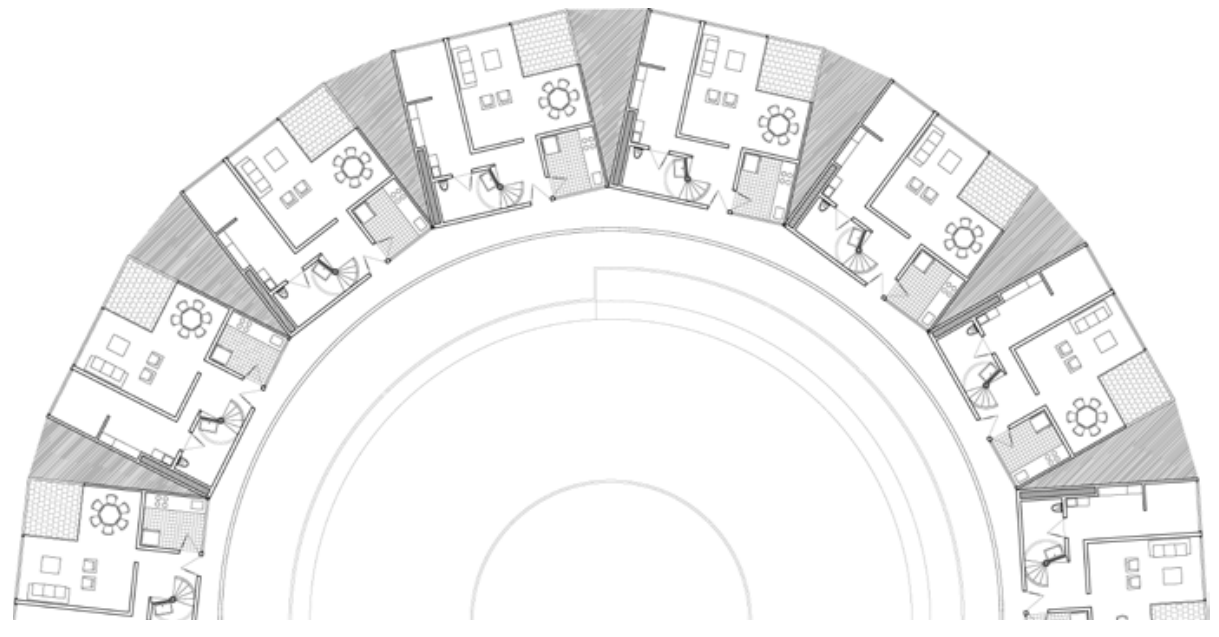

(4) Figura 6. Conjunto de vivienda racionalizado

Fuente: elaboración propia, 2014. CC BY-NC-SA.

Q Figura 7. Crujía deformada de conjuntos

Fuente: elaboración propia, 2014. CC BY-NC-SA.

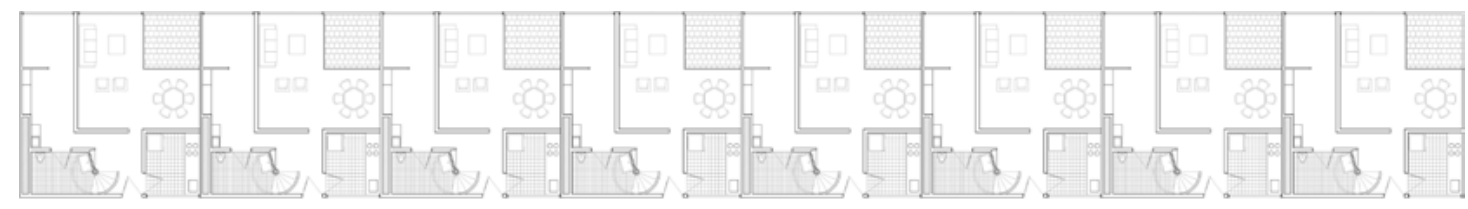

(4) Figura 8. Sistema rectilíneo de crujías

Fuente: elaboración propia, 2014. CC BY-NC-SA.

Al admitir esto se observa cómo la no deformación del sistema hubiese expuesto a las torres con una forma Ilana, monumental y solipsista, que no solo dificulta visuales, luz y ventilación (Figura 9), sino también impide una adecuada disposición dentro del lote (Figura 10). Este sistema delimitado por consideraciones netamente racionales o físicas bien puede asumir el carácter útil del utensilio de Heidegger.

Aceptando que la hipótesis fuese así, aquellos inconvenientes serían enmendados al sustraer algunas de sus viviendas, recreando una forma escalonada e incluyendo el paisaje de los cerros (Figura 11). Sin embargo, el problema de la implantación en el predio aún subsiste por el carácter rectilíneo de la planta de las torres (Figura 12).

Por tanto, aquel sistema rectilíneo de crujías, ahora escalonado, es sometido a deformación, lo que da a las torres su forma singular actual sin cambiar la relación entre sus partes, cerrando así su ciclo de análisis compositivo (Figuras 13 y 14).
La concepción del proyecto nace de un proceso de elaboración que, a diferencia de la arquitectura como utensilio, se realiza en aras de crear algo más eminente: el diálogo entre arquitectura y paisaje.

Una vez dicho esto, si el cometido de las operaciones formales era incluir el paisaje dentro de las torres, habría razón para decir que la arquitectura se prestó como el arte para lograr tal empresa. Una analogía del propósito del templo griego si recordamos que su propósito era acercar hombres y dioses. Esta semejanza que valora la arquitectura como obra arte le dio un carácter más elevado a su diseño, pues su intención no era acatar parámetros ni satisfacer juicios, sino crear paisaje mediante el ejercicio compositivo. Al admitir este concepto se legitima la autonomía del quehacer arquitectónico.

Finalmente, se puede afirmar que esta exposición que reflexiona de manera más extendida sobre las cualidades del proyecto, no solo pretende contribuir con el objetivo de la investigación, 

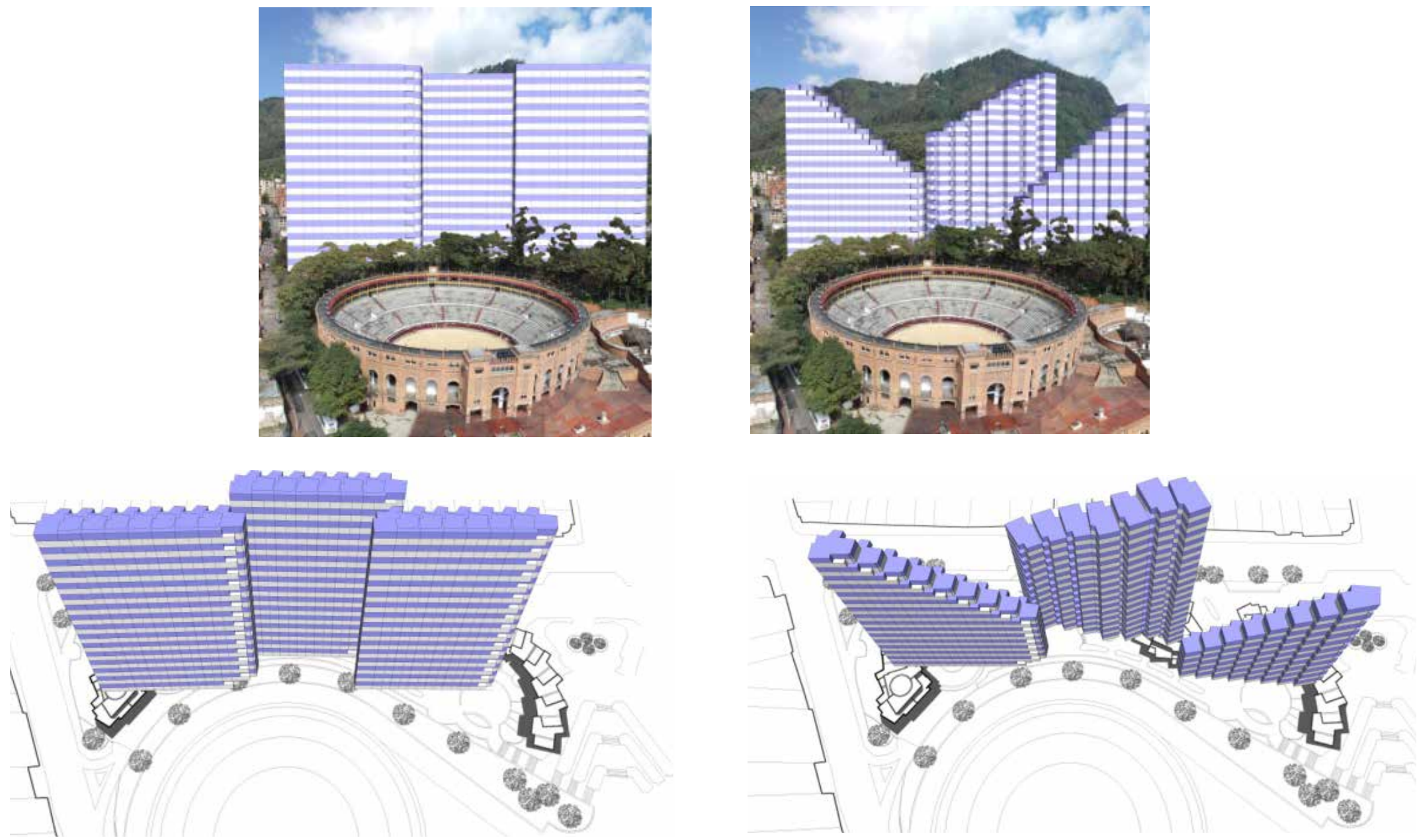

(a) Figura 9. Torres de forma llana y monumental

(A) Figura 10. Inadecuada disposición dentro del lote

Fuente: elaboración propia, 2014. CC BY-NC-SA.

sino también cuestionar aquellas odas alrededor de este proyecto que usualmente lo califican como una obra loable. Tómese como consideración la reiterada proposición de los cerros como algo que Salmona tuvo en consideración al diseñar, y que se suele explicar en diversos apuntes de manera general, superficial e insuficiente como, por ejemplo, la siguiente anotación de Rogelio Salmona, citado por Castro y Villegas (2008): "Las unidades de apartamento de varios tamaños son el resultado de la yuxtaposición de formas geométricas simples, generadas por un sistema de ejes guías" (p. 88). Esta falta de esclarecimiento llevó a realizar un análisis más certero y preciso.

Valorar la arquitectura como obra de arte hace preguntar si este análisis es reproducible en otros proyectos. Por tal razón, esta investigación analiza los siguientes proyectos: Robin Hood Garden, de los arquitectos Peter y Alison Smithson (1972); Inmuebles Villa, de Le Corbusier (1922); 88 viviendas en Carabanchel 17, del arquitecto Nicolás Maruri y ACM Arquitectos (2009), y la Unidad Habitacional de Marsella, de Le Corbusier (1952).

Robin Hood Garden, de Peter y Alison Smithson, es una agrupación que, similar a las Residencias El Parque, hace parte de un sistema de viviendas con piezas de primer y segundo piso, con la diferencia de que este proyecto posee una mayor variedad de viviendas al reordenar sus piezas.

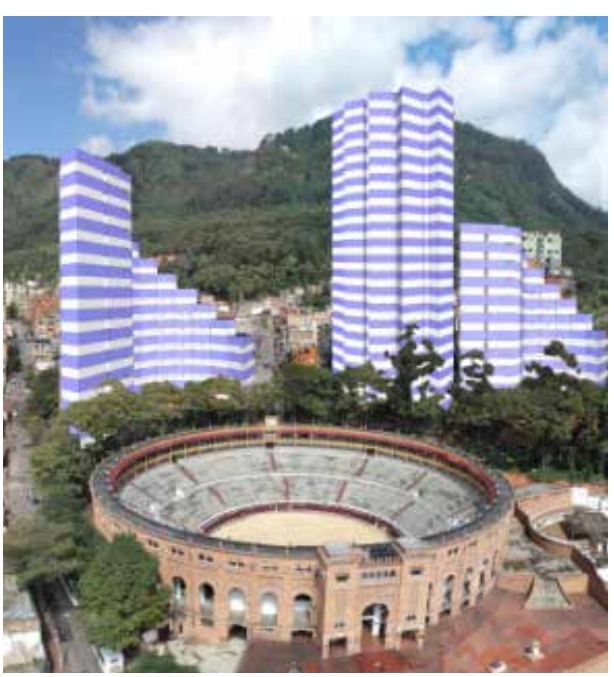

(A) Figura 11. Forma escalonada obtenida al sustraer algunas viviendas

(A) Figura 12. El problema de la implantación

Fuente: elaboración propia, 2014. CC BY-NC-SA.
\& Figura 13. Diálogo entre arquitectura y paisaje (1) Figura 14. Forma singular actual

Fuente: elaboración propia, 2014. CC BY-NC-SA

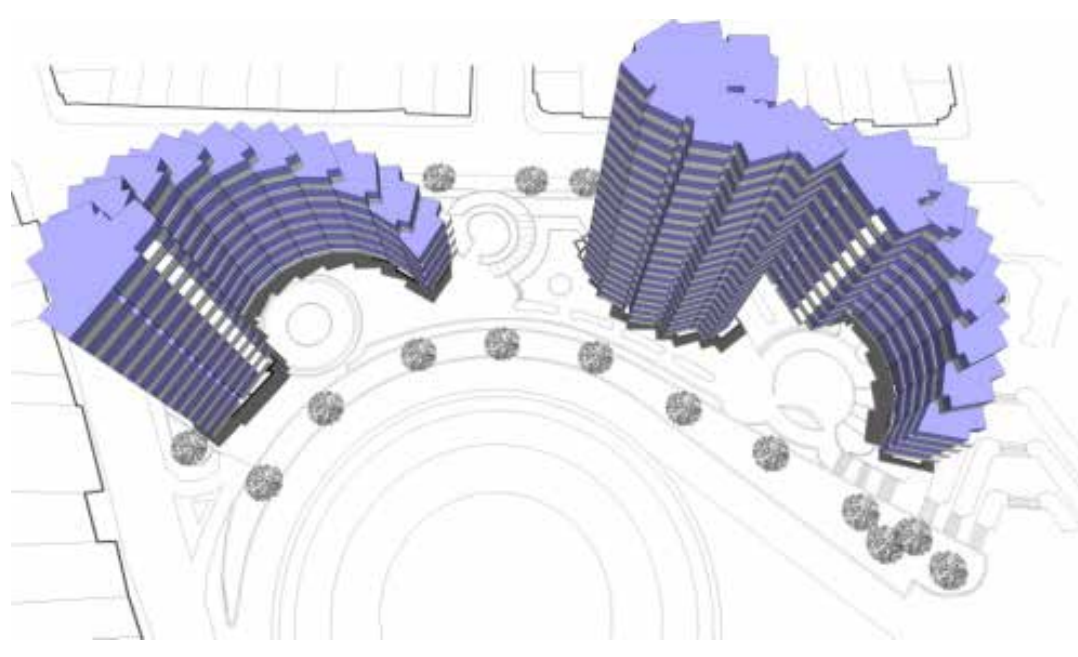

Vol. 


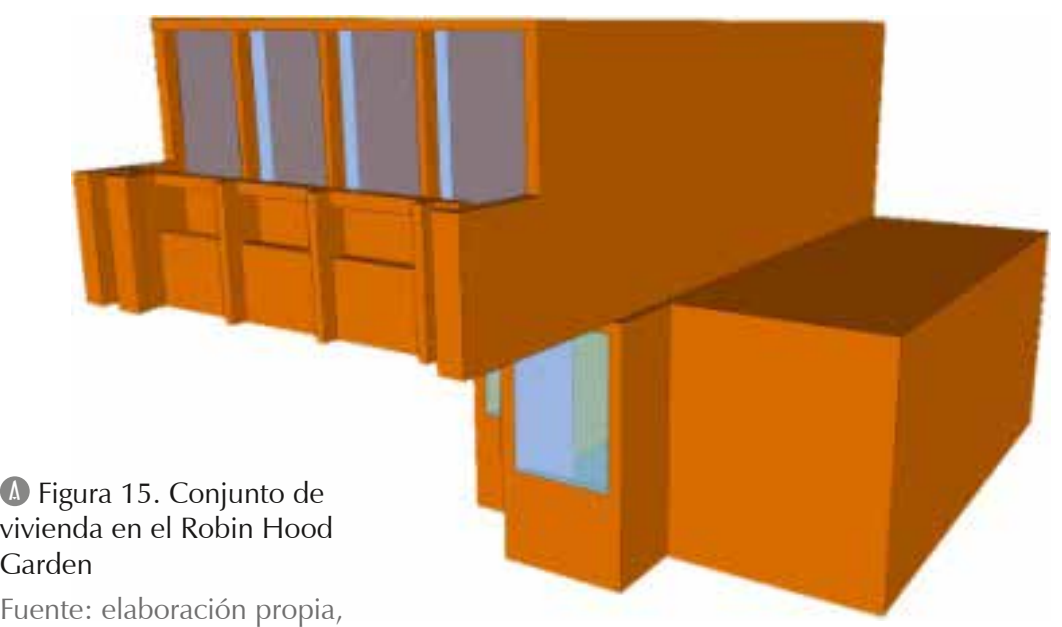

Fuente: elaboración propia, 2014. CC BY-NC-SA.

Para comprender mejor esta última premisa, se somete hipotéticamente una vivienda del Robin Hood Garden a un análisis formal (Figuras 15 y 16).

Como primer paso del análisis se retira uno de los elementos del primer piso de la vivienda (Figura 17) para agregarlo posteriormente a la pieza del segundo piso (Figura 18). El elemento añadido alberga la habitación principal, un baño y un cuarto auxiliar.

Inmediatamente se continúa con una deformación de la nueva pieza, pues se requiere ajustar su unión sin alterar la relación entre elementos (Figura 19), para generar así otra pieza de segundo piso y un conjunto de vivienda (Figuras 20 y 21 ).

Mediante esta misma operación se generan tres conjuntos más de vivienda que, luego de un

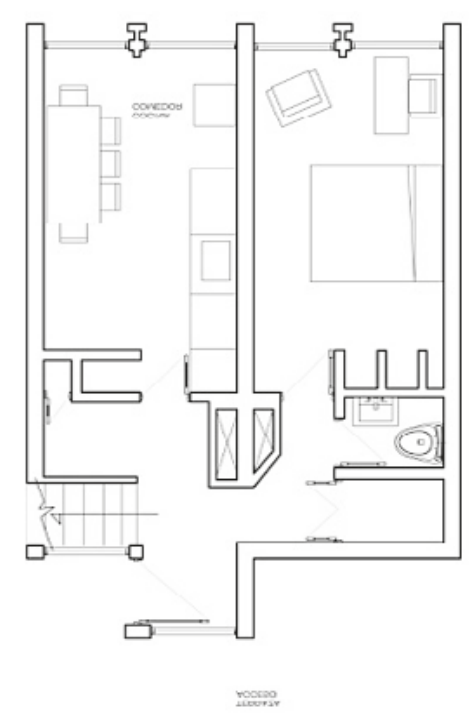

(A) Figura 16. Plantas de una vivienda, primer y segundo piso Fuente: elaboración propia, 2014 Adaptado de Melón (2011). CC BY-NC-SA.
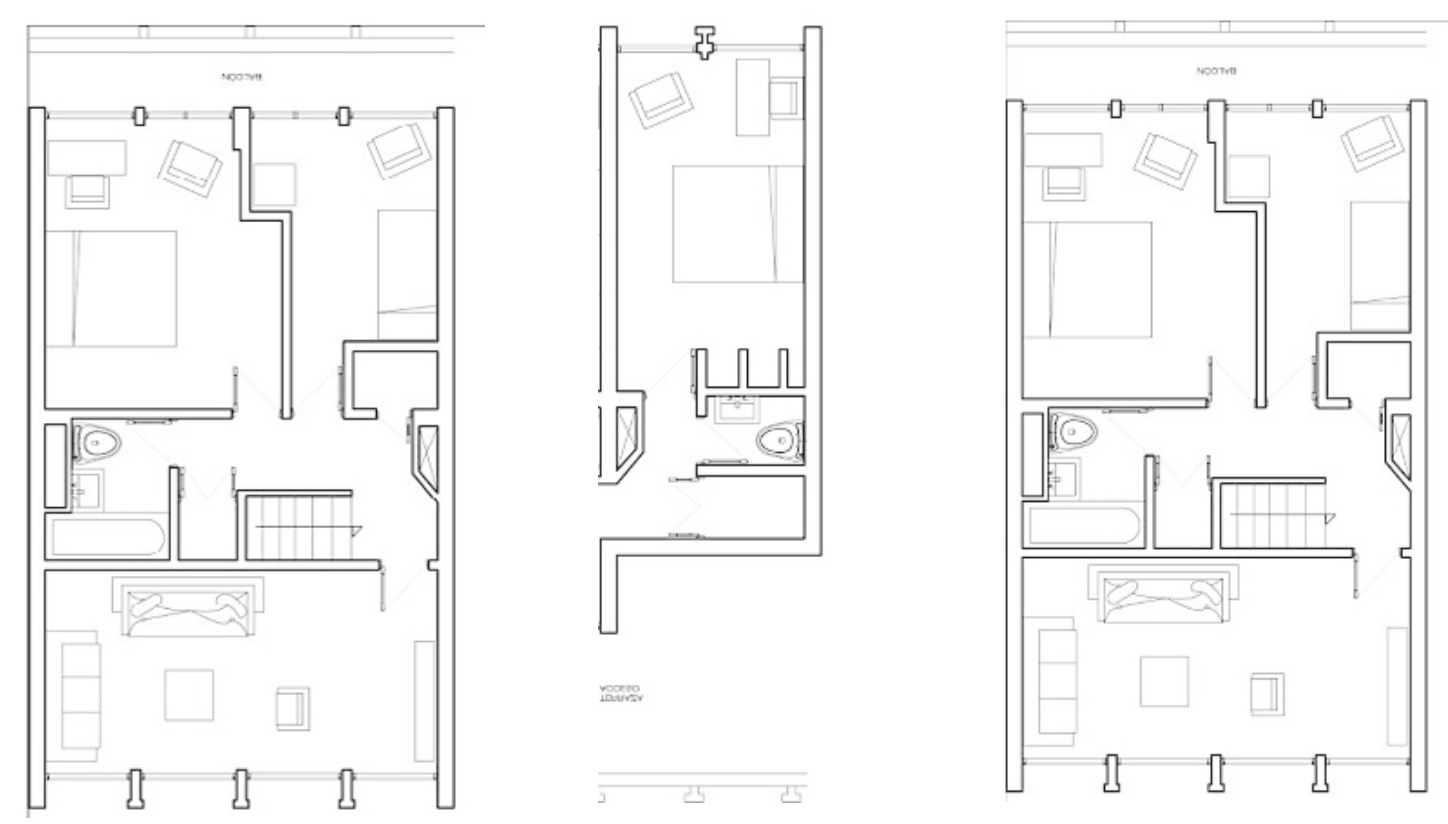

(A) Figura 17. Se toma un elemento de primer piso

Fuente: elaboración propia, 2014. Adaptado de Melón (2011). CC

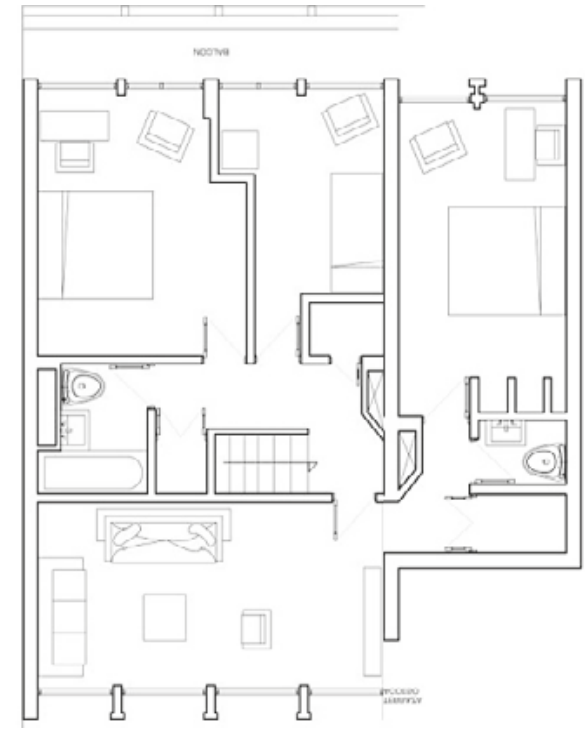

BY-NC-SA.

\& Figura 18. Elemento sumado al segundo piso Fuente: elaboración propia, 2014. Adaptado de Melón (2011). CC BY-NC-SA.
Figura 19. Deformación de la nueva pieza Fuente: elaboración propia, 2014. Adaptado de Melón (2011). CC BY-NC-SA.

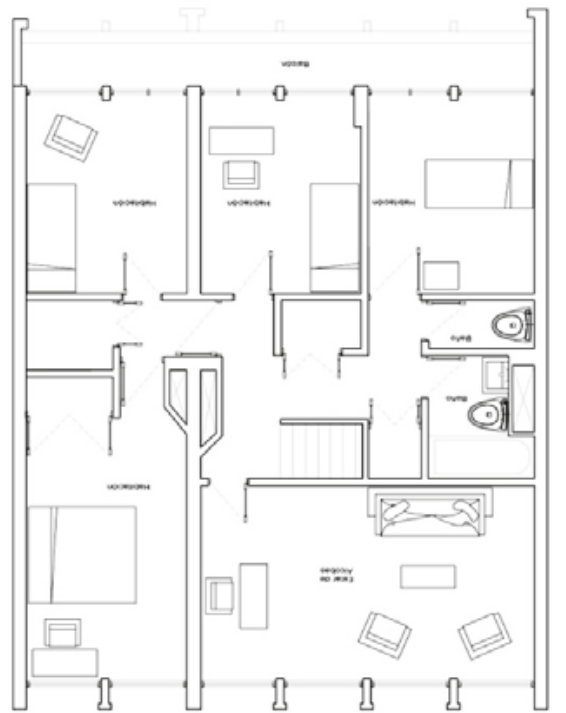


efecto de inversión o de espejo, logran obtener cuatro modelos más para un total de ocho conjuntos de vivienda. En resumen, estos conjuntos que arman el proyecto son variaciones de una misma pieza (Figura 22).

Posteriormente, al juntar estas partes en un sistema edilicio, se genera un nuevo elemento o porche que se constituye en circulación hacia los hogares; un elemento conocido como calle en el cielo (Figura 23) que los arquitectos proyectaron como espacio contemplativo el cual, a diferencia de las Residencias El Parque, alude al paisaje y es cerramiento de una zona verde como pieza contemplativa (Figura 24). Este aspecto puntual de la inclusión del paisaje como pieza interior del conjunto no se aprecia en el proyecto bogotano.

El sentido que dan estas variaciones a la conformación del sistema es el resultado de una operación que manejó la formalidad de una pieza en la creación de un vínculo entre zonas verdes y viviendas.

Estos espacios con finalidad contemplativa se pueden verificar y comprender al estudiar el modelo Inmuebles-Villas de Le Corbusier, paralelo a Carabanchel 17 de Nicolás Maruri.

(1) Figura 22. Variaciones de una pieza Fuente: elaboración propia, 2014. CC BY-NC-SA.
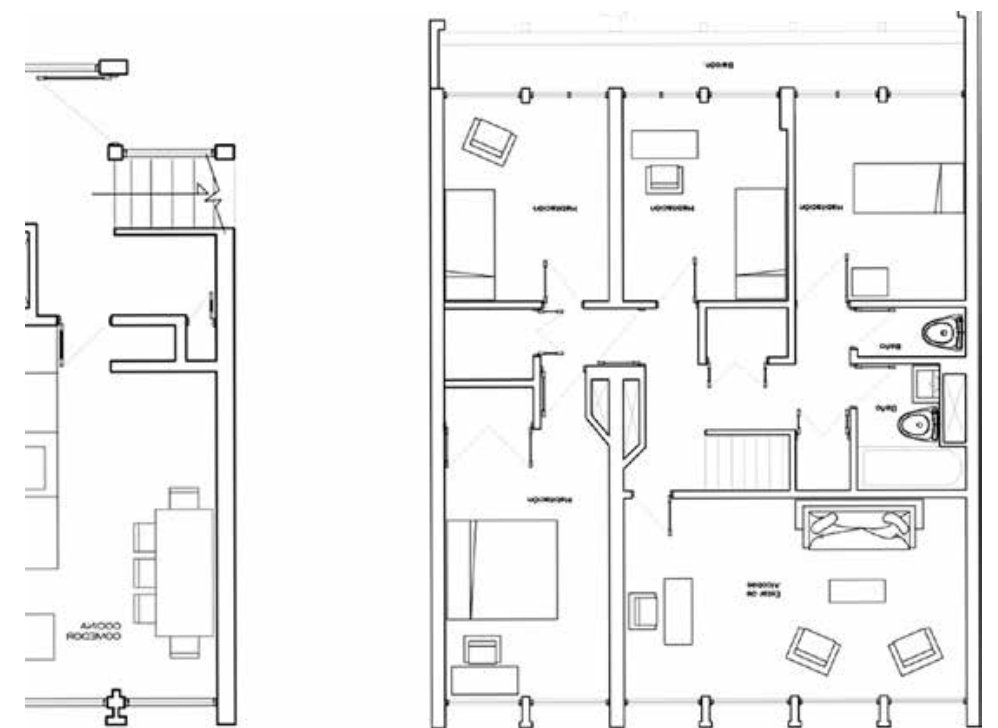

(A) Figura 20. Una nueva planta de primer y segundo piso

Fuente: elaboración propia, 2014 Adaptado de Melón (2011). CC BY-NCSA.

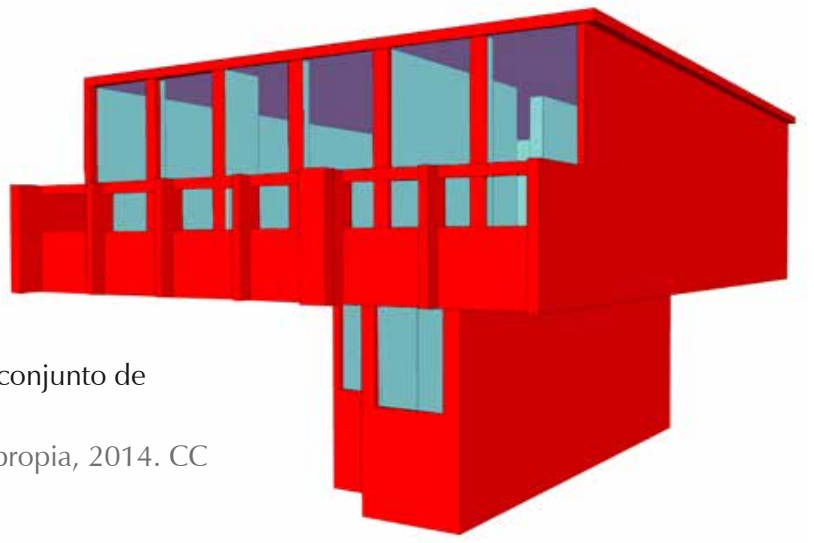

$\otimes$ Figura 21. Nuevo conjunto de

Fuente: elaboración propia, 2014. CC BY-NC-SA.

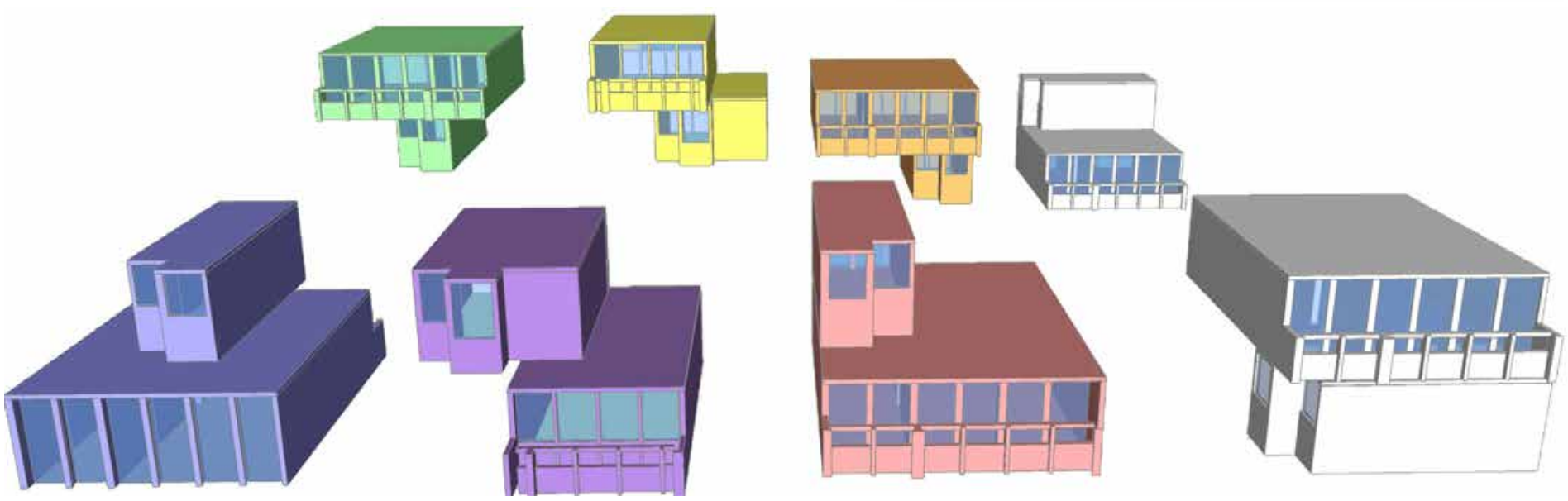
vivienda

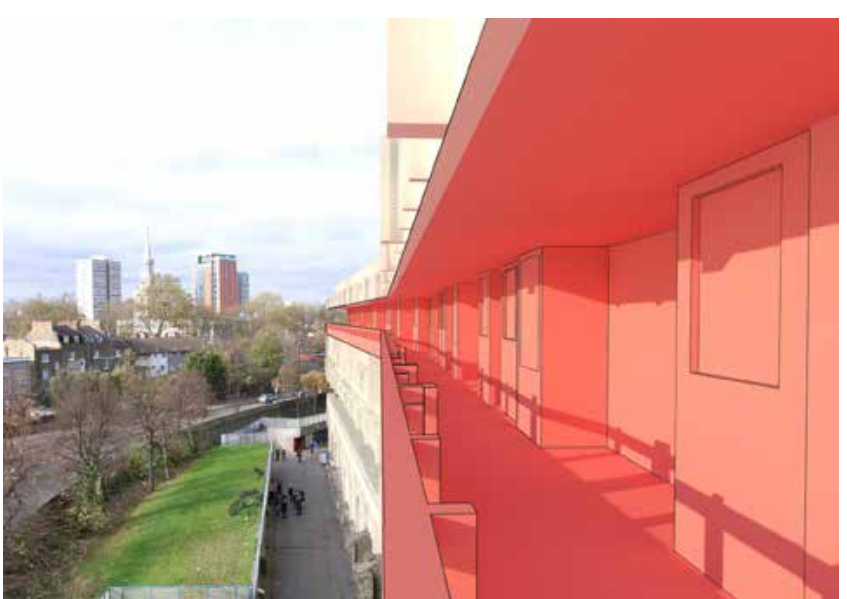

(A) Figura 23. Calle en el cielo

Fuente: elaboración propia, 2014. Adaptada de Cadman (2008). CC BY-NC-SA.

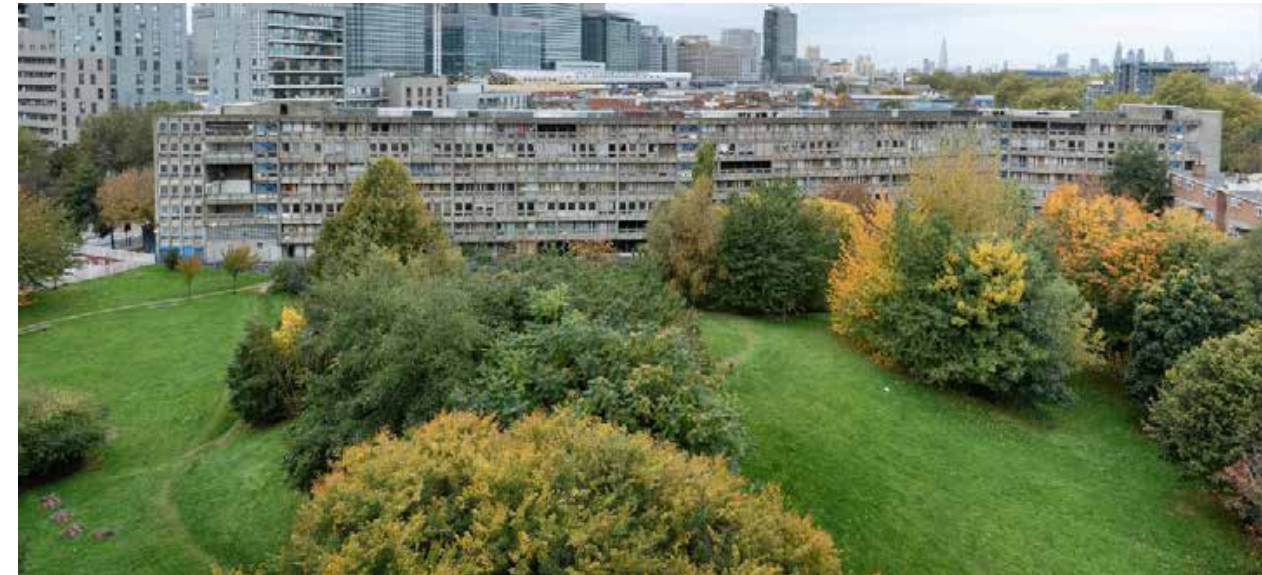

(A) Figura 24. Zona verde para conjuntos de vivienda Fuente: seier+seier, 2015. CC BY. 

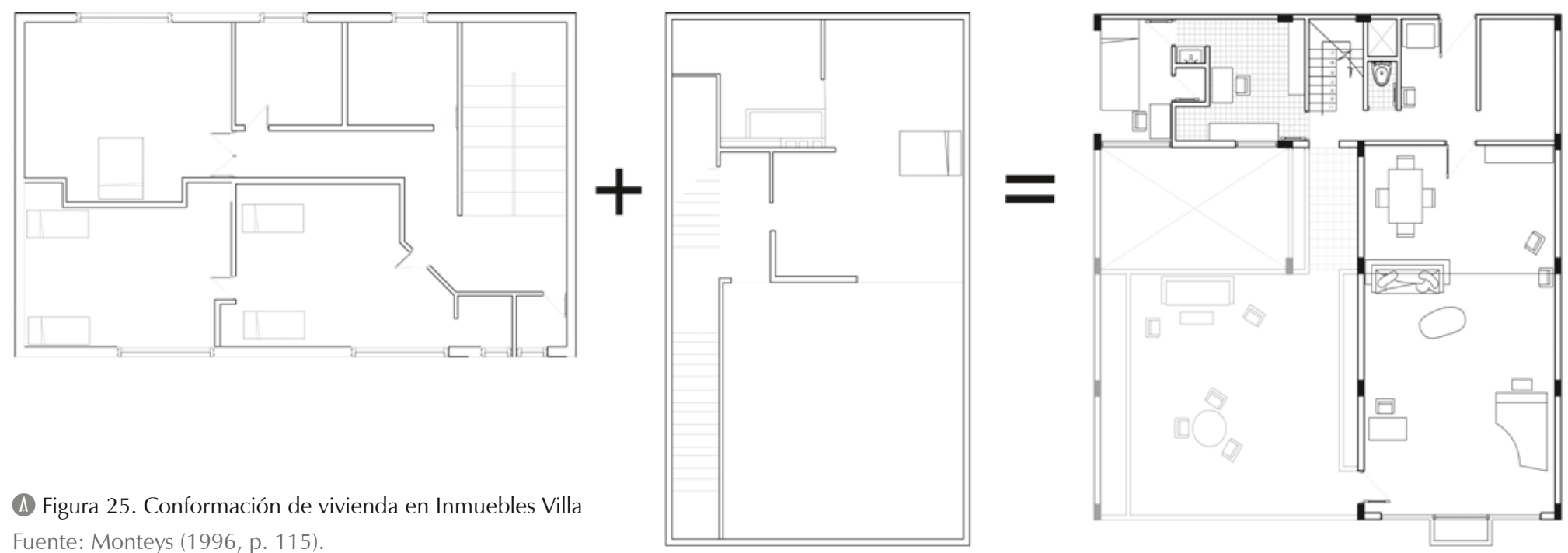

(4) Figura 25. Conformación de vivienda en Inmuebles Villa Fuente: Monteys (1996, p. 115).

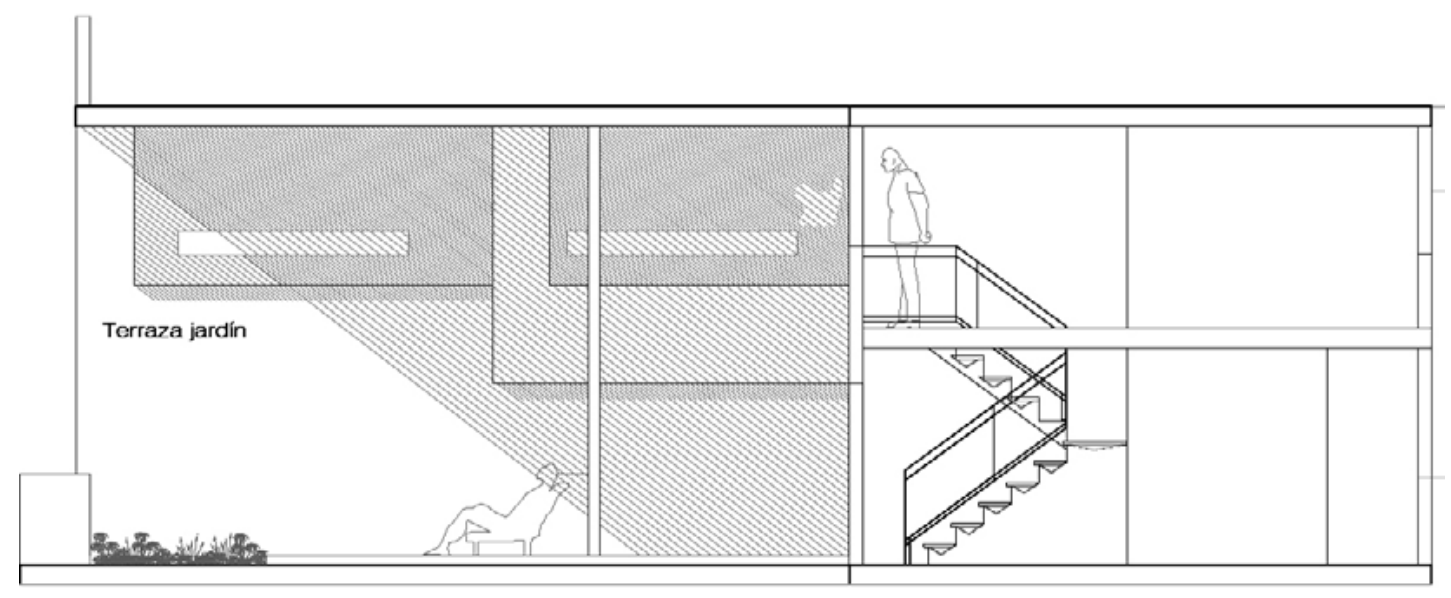

P Figura 26. Aplicación del jardín de $\checkmark$ Le Corbusier en el proyecto de Maruri Fuente: elaboración propia. Superior adaptado de Monteys (1996); inferior adaptado de ACM Arquitectos (2004).

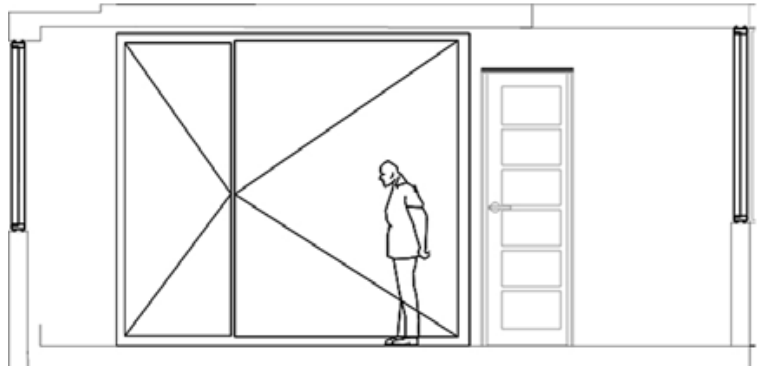

Inicialmente se expone cómo Carabanchel 17 es una aplicación de la tesis de Nicolás Maruri sobre la vivienda de Le Corbusier, la cual explica a Inmuebles-Villa como una propuesta poseedora de un "espacio exterior capturado" (Maruri, 2006), en referencia a una de las piezas que propone el sistema Villas, formada por dos viviendas diseñadas previamente por Le Corbusier: la Casa Citröhan y la Casa Dom-Ino (Maruri, 2006) (Figura 25).

Primeramente, se precisa que el papel de las Casas Citröhan y Dom-Ino en la generación de espacios para contemplar el paisaje radica en su unión para crear el actual sistema villa. De aquella unión se genera un conjunto de viviendas que contiene una nueva pieza a la cual Le Corbusier concibe como un jardín o un espacio al sol, y que permite la continuación del entorno hacia el interior de la vivienda como propuesta para capturar el exterior dentro de la casa. Esta pieza se aplica posteriormente con algunas variaciones a un modelo más contemporáneo en la ciudad de Madrid (Figura 26).

Al estudiar el proyecto de Nicolás Maruri se habla de un sistema de conjuntos de vivienda que emplea la pieza heredada de Le Corbusier: el jardín o espacio al sol (Figura 27).

Este proyecto, similar al Robin Hood Garden o incluso a las Torres del Parque (Figura 28), es un sistema que también se somete al proceso de deformación en su implantación (Figura 29) y que, además, genera una pieza o recinto en su interior que se presta como plaza (Figura 30).

La particularidad de este caso es la adición de la pieza de Inmuebles Villa que, como se mencionó, introduce el exterior dentro de la vivienda, es decir, un recinto rodeado por casas. De modo que el proyecto de Maruri podría suponer un diálogo con el paisaje en su plaza interior, empleando el espacio al sol de Le Corbusier de manera análoga a la calle en el cielo de los Smithson (Figura 31).

Ambos proyectos, el de Le Corbusier y el de Maruri, poseen una pieza que introduce el exterior en cada vivienda. Creada en Inmuebles-Villas para incluir el exterior dentro del hogar, y transformada en Maruri no solo para atrapar el exterior, sino para proyectar el interior del sistema como parte de la edificación. Esta pieza 

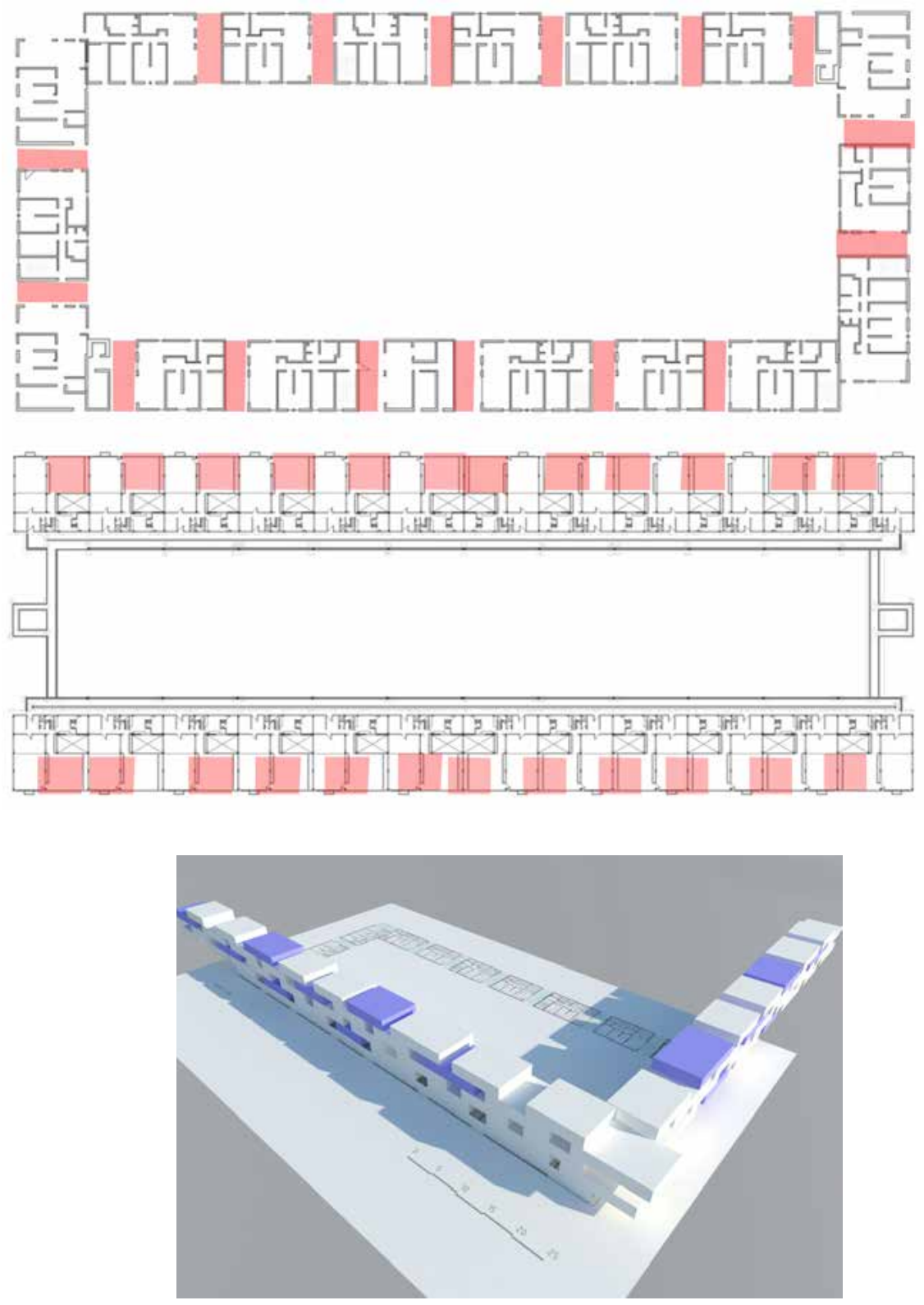

(A) Figura 29. Deformación del sistema

Fuente: elaboración propia, 2014. CC BY-NC-SA.
\& Figura 27. El jardín del proyecto de Le Corbusier adaptado a un proyecto más contemporáneo: Caravanchel 17

Fuente: elaboración propia. Superior adaptado de ACM Arquitectos (2004); inferior adaptado de Monteys (1996).

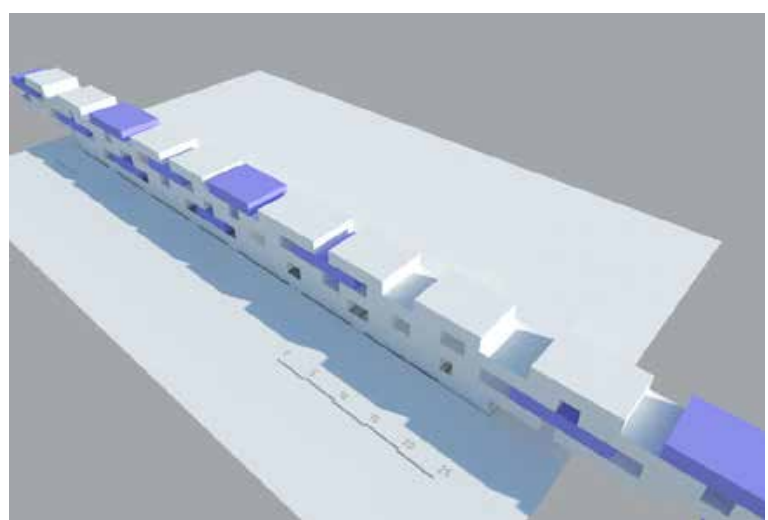

(A) Figura 28. Sistema de vivienda Fuente: elaboración propia, 2014. CC BY-NC-SA.

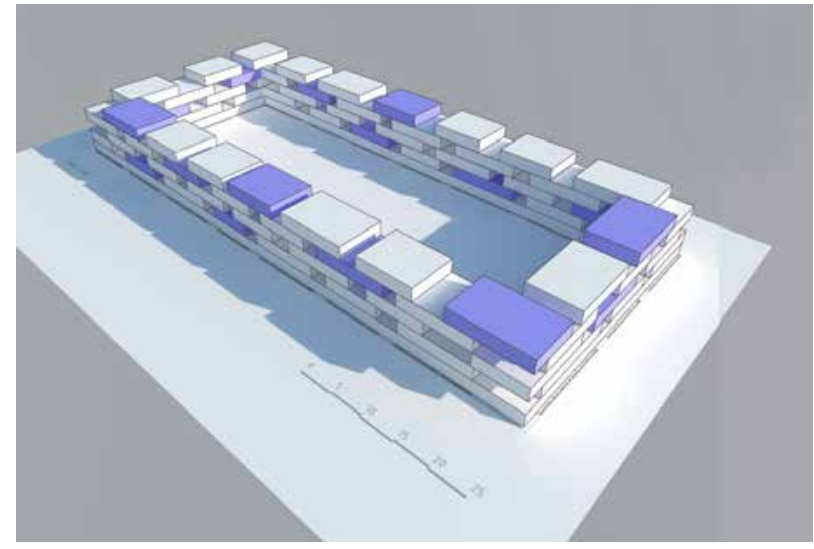

(A) Figura 30. Generación de plaza o recinto Fuente: elaboración propia, 2014. CC BY-NC-SA. en Maruri, que atrapa el paisaje al interior del hogar, se observa como rastro de una operación que pretendía captar el paisaje.

Los análisis realizados a Carabanchel 17 y a Inmuebles-Villa no pretendían hacer énfasis en la composición de los elementos dentro de la vivienda (alcoba, sala, etc.), sino aludir a la pieza de Le Corbusier que, mediante una deformación del sistema, generó un proyecto con un papel contemplativo. Una conjetura que se aplicó también en el análisis del proyecto de vivienda de Le Corbusier en la ciudad de Marsella (Figuras 32 y Figura 33).

Con respecto a la Unidad Habitacional se puede anotar que es un sistema de conjuntos de viviendas en forma de " $L$ " vistas desde su sección, y que esta investigación analizó a partir de esta posición. En el sistema de Marsella las piezas de primer y segundo piso generan un elemento que indica circulación, similar a la calle en el cielo, como lugar que reunía la parte contemplativa de un paisaje cercano.

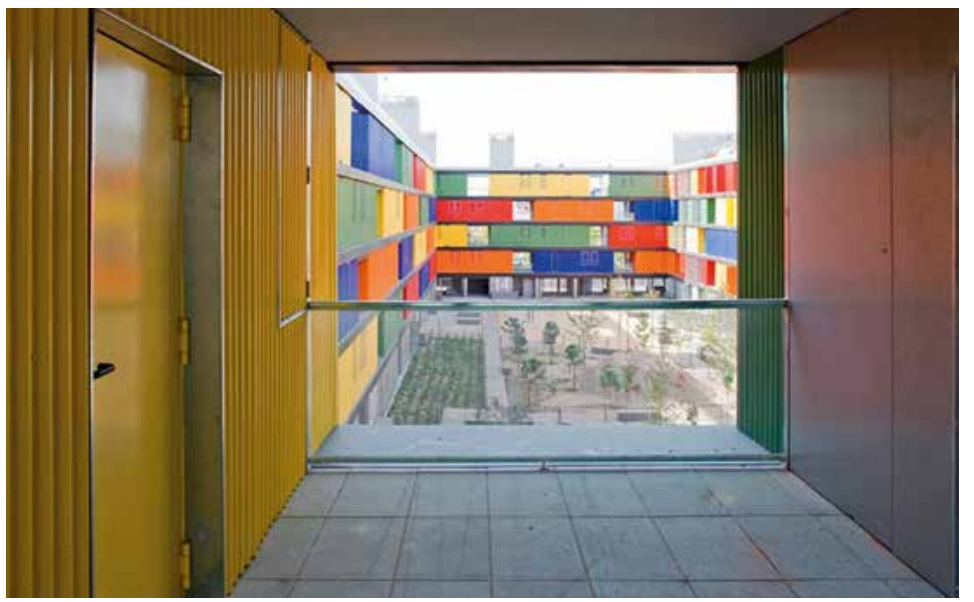

No obstante, en la Unidad Habitacional la relación entre estos conjuntos de vivienda hace de este elemento un corredor oscuro (Figura 32). Esta pieza (el corredor) lleva posteriormente a A Figura 31. La plaza a través de la pieza de Le Corbusier Fuente: Guzmán (2009). (c) Copyright los Smithson a proponer el Robin Hood Garden como respuesta a la Unidad Habitacional. Además de ello, la lectura en sección también permite identificar la pieza usada en Inmuebles Villa, al igual que el caso Maruri que, como se explicó, permite introducir una parte contemplativa dentro del hogar (Figura 34). 

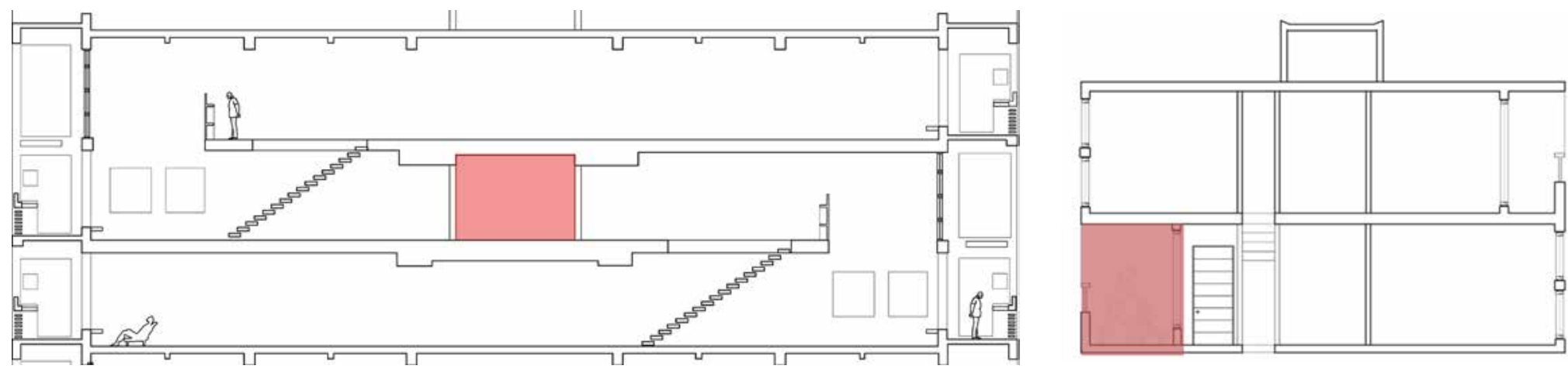

(4) Figura 32. Corredor en Unidad Habitacional de Marsella
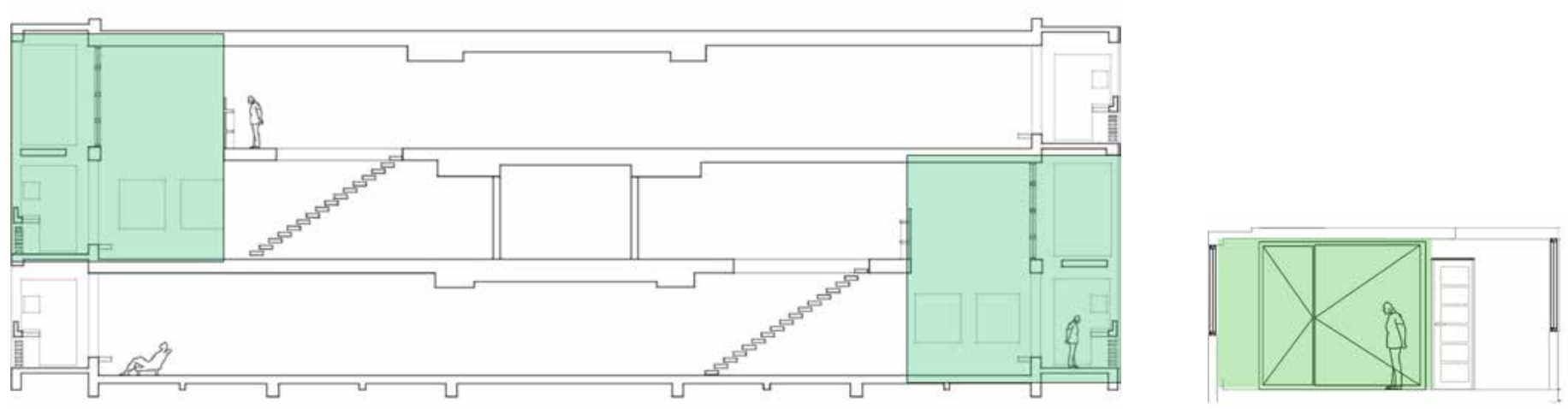

A Figura 34. Pieza de la Unidad

Habitacional reproducida en Carabanchel

Fuente: elaboración propia, 2014. Izquierda adaptada de Monteys (1996); derecha adaptada de ACM Arquitectos (2004).

\section{Conclusiones}

- En el caso observado por Koolhaas en las edificaciones de Nueva York, su aproximación a lo que debería considerarse por calidad no ofrece respuestas en términos de arquitectura, pero sí la identifica como una virtud que se concreta fuera de la disciplina. Después de todo, en Koolhaas la calidad se sustenta en consideraciones prácticas o físicas que obedecen a un procedimiento técnico más que a un ejercicio formal.

- Por otro lado, Tarchópulos y Ceballos, además de incluir estas mismas consideraciones prácticas, las complementan conjuntamente añadiendo la pauta de satisfacción del usuario. Y aunque el trabajo de Tarchópulos no se enfoque principalmente en cuestiones de tipo formal, no se demerita cuando afirma que el aspecto físico por sí solo es insuficiente, pues, de no ser así, el énfasis en los aspectos físicos podría justificar a las Residencias El Parque expuestas como un muro contra los cerros, ya que han sido erigidas sobre procedimientos técnicos al modo de Nueva York.

La calidad se inferiría por la correcta ejecución de un instructivo. De esta manera, el rol de la arquitectura se adoptaría servil y supeditado a formas no propias del ejercicio compositivo, al modo del proyecto de la Ciudad de la Cultura de Galicia. El papel de la disciplina en las Residen- cias se distinguiría útil por su heteronomía hacia factores externos a la profesión arquitectónica.

Por otra parte, hay que mencionar también el aspecto subjetivo, del cual hablan Tarchópulos y Ceballos, y compararlo con el análisis del Robin Hood Garden. Se dijo previamente que una de las intenciones de la calle en el cielo es prestarse como un lugar para el dinamismo y encuentro de sus usuarios. Un aspecto que bien puede entenderse como el punto personal o de satisfacción de los residentes al que aspiran Tarchópulos y Ceballos para otorgar calidad a la vivienda. Pero hay que dejar dicho lo contrario. La satisfacción del residente no es el hecho que le da calidad al Robin Hood Garden en los términos que propone este trabajo, pues de ser así, el goce del usuario puede ser medido o determinado a partir de otras disciplinas. Operar a partir de las sensaciones y percepciones del usuario de manera particular restringiría la arquitectura a un aspecto cósico. Su característica principal, y sobre la que se basa este trabajo, es haber enmarcado un paisaje mediante un procedimiento compositivo. Un proceso que deformó y reorganizó sus variaciones de viviendas en orden a integrar una gran zona verde como un elemento más de diseño y nacido del mismo proceder arquitectónico. Una faceta que esta investigación propone como un elemento para definir la calidad del proyecto partiendo del proyectar arquitectónico. 
Asimismo, Carabanchel 17, al igual que las Residencias El Parque, pretende otorgarle a su proyecto la misma cualidad positiva a través de un proceso de deformación de sus piezas, de manera que una de sus particularidades es precisamente la inclusión del paisaje empleando la pieza de Le Corbusier. En Caravanchel y en Inmuebles Villa se incluye dicho paisaje en las viviendas, del mismo modo que Monteys propone proyectar el exterior al interior salvo con una excepción: Monteys, si bien propone esta proyección con el fin de satisfacer al usuario, los proyectos mencionados no toman esa característica como bastión de sus diseños. La inclusión del exterior de Monteys es la función de la pieza cedida de un proyecto a otro (Le Corbusier a Maruri) para introducir el paisaje de la plaza Caravanchel al hogar.

Estos casos de estudio muestran cómo las operaciones de composición en cada proyecto se realizaron en aras de integrar el paisaje dentro de ellos. Una finalidad que describe a la arquitectura, no solo como la técnica para lograr algo eminente, sino más bien arquitectura como obra de arte.

De modo que, a partir de esta conjetura sobre cómo la arquitectura incluye al paisaje mediante la formalidad, esta investigación concluye con la siguiente hipótesis: “Un elemento para valorar la calidad en la vivienda colectiva, entendiendo la arquitectura como obra de arte, es la creación de paisaje a partir de operaciones formales" (Valderrama, 2014, p. 63).

La calidad de la arquitectura en estos proyectos se definió desde el quehacer profesional. Los cinco proyectos legitiman su calidad exponiendo la pieza característica que generaron en su composición. La calidad garantiza la recuperación de la autonomía de la arquitectura y la sitúa como el recurso que dio un carácter excepcional a aquellas edificaciones, es decir, calidad arquitectónica, dada en térmicos de diseño compositivo al haber sido la arquitectura una técnica para crear paisaje. Esta forma de valorar el diseño arquitectónico se ofrece a todo estudiante o profesional que quiera darle valía a su diseño desde el ejercicio compositivo, y, asimismo, asegurar a la disciplina su autonomía.

Finalmente, se comenta que las indicaciones hechas alrededor de la valoración de calidad (arquitectura como cosa y como utensilio) no pretenden deslegitimar o desacreditar aquellas maneras de proceder, pero sí proponer al arquitecto que las sitúe en un plano paralelo al momento de diseñar formalmente, pues son adyacentes y no directas al ejercicio compositivo.

\section{Referencias}

ACM Arquitectos (2004). 81 viviendas en Carabanchel para la EMV. [Mensaje en un blog]. Amann Canovas Maruri. Recuperado de http://amanncanovasmaruri.blogspot.com. co/search/label/2009\%20CARABANCHEL

Arango, S. (1989). Historia de la arquitectura en Colombia. Bogotá: Universidad Nacional de Colombia.

Armesto, A. (2008). Apuntes sobre la autonomía de la arquitectura respecto a la vida, el sitio y la técnica. En Foro crítica: arquitectura y naturaleza. Arquitectura contra Natura (pp. 79-119). Alicante: Colegio Territorial de Arquitectura de Alicante.

Cadman, S. (2008). Streets in the Sky. [Fotografía] (CC BY-SA). Recuperado de: http://flickr. com/photos/98115025@N00/3058342144

Castro, R. y Villegas, B. (2008). Rogelio Salmona: Tributo. Bogotá: Villegas Editores.

Correal Pachón, G. D., Eligio-Triana, C., Páez Calvo, A., Francesconi Latorre, R., Rojas Quiñones, P., Quiroga Molano, E., \& Salinas, A. M. (2015). Aprendizaje, composición y emplazamiento en el proyecto de arquitectura. Un diálogo entre las aproximaciones tipológica y analógica (1. ${ }^{\mathrm{a}}$ ed.). Bogotá: Universidad Católica de Colombia - Universidad Piloto de Colombia. Recuperado de http://repository.ucatolica.edu.co/handle/10983/14956

Ferriss, H. (1929). The Metropolis of Tomorrow. New York: Ives Washburn. Recuperado de: https://archive.org/details/mettomo00ferr/ page/n5

Guzmán, M. (2009). 81 viviendas en Carabanchel para la EMV, Madrid. ImágenesSubliminal. Recuperado de: http://imagensubli minal.com/81-viviendas-en-carabanchel-para-la-emv/?lang =es
Heidegger, M. (2010 [1950]). El origen de la obra de arte. En M. Heidegger, Caminos del bosque (pp. 11-59). Madrid: Alianza Editorial.

Kant, I. (2011). Critica del juicio. Madrid: Librerías de Francisco Iravedra.

Koolhaas, R. (2004). Delirio de Nueva York. Barcelona: Gustavo Gili.

Koolhaas, R. (2011). Grandeza, o problema de la talla. Barcelona: Gustavo Gili.

Maruri, N. (2006). La cabina de la máquina. Evolución del espacio vertical en los proyectos de Le Corbusier. Madrid: Universidad Politécnica de Madrid, Departamento de Proyectos Arquitectónicos. Recuperado de: http://oa.upm.es/340/

Melón, A. (2011). ¿Rehabilitación o demolición?: habitando Robin Hood Gardens en el siglo XXI. [Mensaje en un blog]. La ciudad viva. Recuperado de http://www.laciudadviva.org/blogs/?p=11160

Monteys, X. (1996). La gran máquina: la ciudad en Le Corbusier. Barcelona: Serbal.

Monteys, X. (2012). Rehabilitar en nueve episodios. Barcelona: Lampreave.

Rojas, P. (2011). Análisis, analogía y transformación. Diseño de un método de aprendizaje de la composición arquitectónica. Alarife: Revista de Arquitectura, 22, 80-101. Recuperado de https://dialnet.unirioja.es/servlet/articulo?codigo $=3861209$

Rojas, P. (2012). Aparejo y deformación: lecciones de composición revisadas en el edificio para la facultad de economía de Fernando Martinez Sanabría (Tesis de maestría). Universidad Nacional de Colombia, Bogotá. Recuperado de: http://bdigital.unal.edu. co/10808/
Rojas, P. (Comunicación personal, 10 de agosto de 2013). La deformación en las Torres del Parque (J. Valderrama, entrevistador).

Rojas-Quiñones, P. y Eligio-Triana, C. (2015). La composición. En G.D. Correal Pachón, R. Francesconi Latorre, P. Rojas Quiñones, C. A. Eligio Triana, E. Quiroga Molano, A. Páez Calvo, y A. M. Salinas. Aprendizaje, composición y emplazamiento en el proyecto de arquitectura: diálogo entre las aproximaciones tipológica y analógica (pp. 45-109). Bogotá: Universidad Católica de Colombia y Universidad Piloto de Colombia. Recuperado de: http://hdl.handle.net/10983/14956

seier+seier (2015). The Smithsons, Peter and Alison Smithson, Architects: Robin Hood Gardens, London, 1966-1972 [Fotografía] (CC BY). Recuperado de: https://www.flickr. com/photos/seier/22940844585

Studio 8 (2013). Unite d'habitation, Marseille: Case Study. Housing + Wiki Sheffield School of Architecture. Recuperado de: http://housingplus.wikidot.com/unite-d-habitation

Tarchópulos, D. y Ceballos, O. (2003). Calidad de la vivienda dirigida a los sectores de bajos ingresos en Bogotá. Bogotá: Ceja.

Téllez, G. (2013). Rogelio Salmona. Obra completa, 1959-2005. Bogotá: Escala.

Valderrama, J. C. (2014). Cinco proyectos de vivienda colectiva: un ensayo sobre la calidad arquitectónica desde la forma (Tesis de pregrado). Bogotá, Universidad Piloto de Colombia. Recuperado de http://polux.unipiloto.edu.co:8080/00001643.pdf 


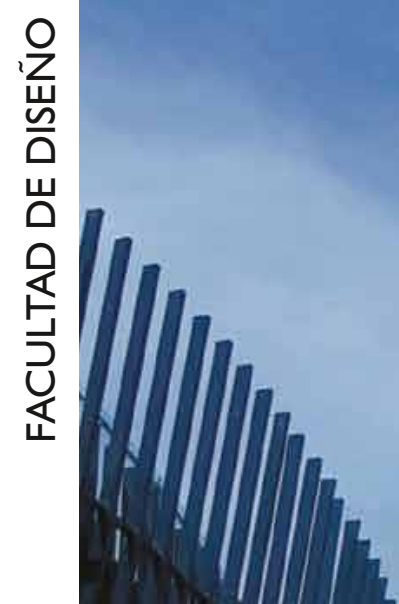

Vol.

\section{Nro. 1REVISTA DE ARQUITECTURA}
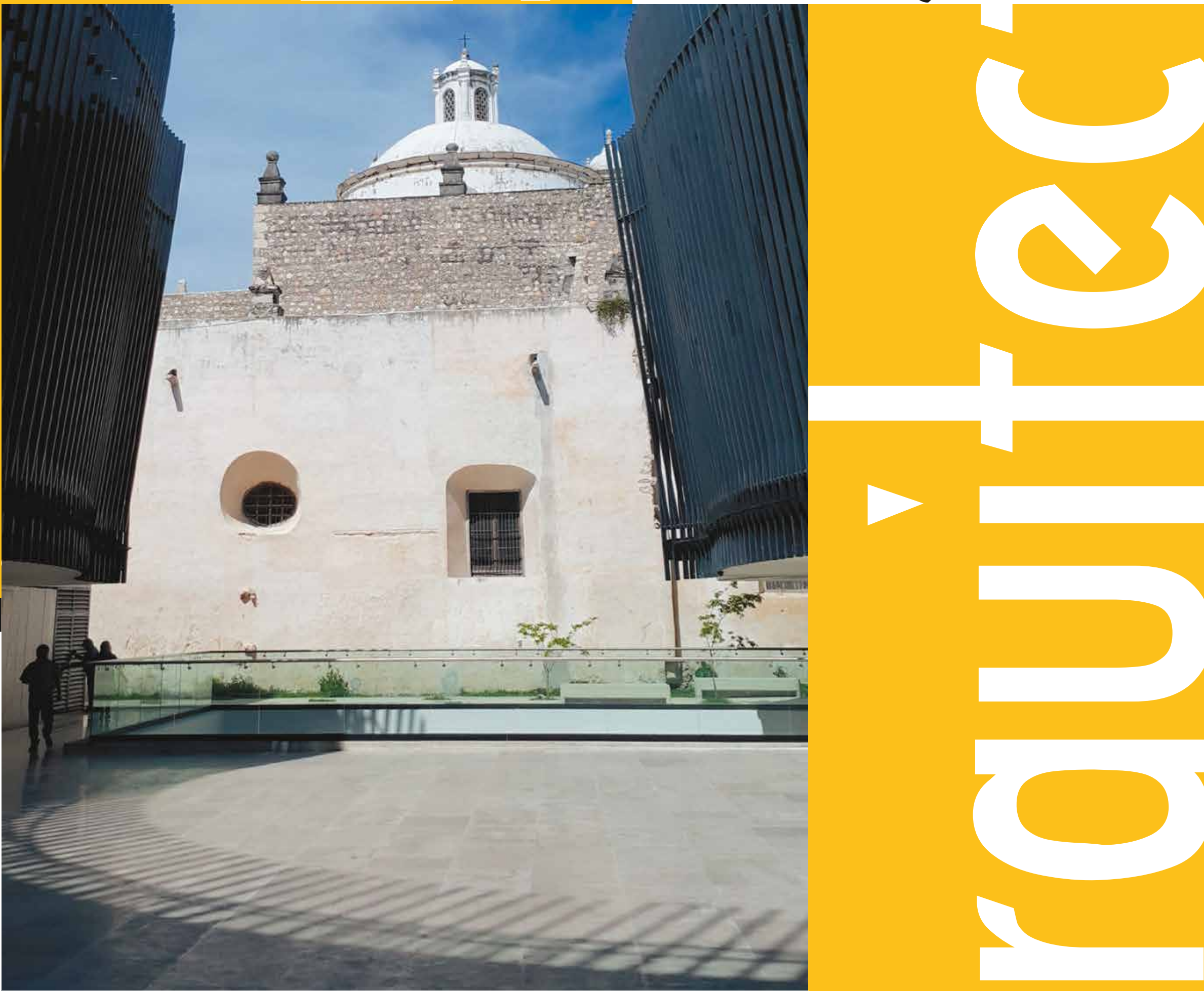
A) Portada: Palacio de la Música y Rectoria El J Júśs Tercera Orden. Mérida, Yucatán (México).

\section{() (1) $\Theta$}

A Orientación editorial

\section{Enfoque y alcance}

La Revista de Arquitectura (Bogotá) ( (ISSN 1657-0308 Impresa y E-ISSN 2357-626X en línea) es una publicación seriada de acceso abierto, arbitrada mediante revisión por pares (doble ciego) e indexada, en donde se publican resultados de investigación originales e inéditos.

Está dirigida a la comunidad académica y profesional de las áreas afines a la disciplina. Es editada por la Facultad de Diseño y el Centro de Investigaciones (CIFAR) de la Universidad Católica de Colombia en Bogotá (Colombia).

La principal área científica a la que se adscribe la Revista de Arquitectura (Bogotá) según la OCDE es:

Gran área: 6. Humanidades

Área: 6.D. Arte

\section{Disciplina: 6D07. Arquitectura y Urbanismo}

También se publican artículos de las disciplinas como 2A02, Ingeniería arquitectónica; 5G03, Estudios urbanos (planificación y desarrollo); 6D07, Diseño.

Los objetivos de la Revista de Arquitectura (Bogotá) son:

- Promover la divulgación y difusión del conocimiento generado a nivel local, nacional e internacional

- Conformar un espacio para la construcción de comunidades académicas y la discusión en torno a las secciones definidas.

- Fomentar la diversidad institucional y geográfica de los autores que participan en la publicación.

- Potenciar la discusión de experiencias e intercambios científicos entre investigadores y profesionales.

- Contribuir a la visión integral de la arquitectura, por medio de la concurrencia y articulación de las secciones mediante la publicación de artículos de calidad.

- Publicar artículos originales e inéditos que han pasado por revisión de pares, para asegurar que se cumplen las normas éticas, de calidad, validez científica, editorial e investigativa.

- Fomentar la divulgación de las investigaciones y actividades desarrolladas en la Universidad Católica de Colombia.
Palabras clave de la Revista de Arquitectura (Bogotá): arquitectura, diseño, educación arquitectónica, proyecto y construcción, urbanismo.

Idiomas de publicación: español, inglés, portugués y francés. Título abreviado: Rev. Arquit.

\section{Titulo corto: RevArq}

\section{Políticas de sección}

La revista se estructura en tres secciones correspondientes a las líneas de investigación activas y aprobadas por la institución, y dos complementarias, que presentan dinámicas propias de la Facultad de Diseño y las publicaciones relacionadas con la disciplina.

Cultura y espacio urbano. En esta sección se publican los artículos que se refieren a fenómenos sociales en relación con el espacio urbano, atendiendo aspectos de la historia, el patrimonio cultural y físico, y la estructura formal de las ciudades y el territorio.

Proyecto arquitectónico y urbano. En esta sección se presentan artículos sobre el concepto de proyecto, entendido como elemento que define y orienta las condiciones proyectuales que devienen en los hechos arquitectónicos o urbanos, y la forma como estos se convierten en un proceso de investigación y nuevo de conocimiento. También se presentan proyectos que sean resultados de investigación, los cuales se validan por medio de la ejecución y transformación en obra construida del proceso investigativo. También se contempla la publicación de investigaciones relacionadas con la pedagogía y didáctica de la arquitectura, el urbanismo y el diseño.

Tecnología, medioambiente y sostenibilidad. En esta sección se presentan artículos acerca de sistemas estructurales, materiales y procesos constructivos, medioambiente y gestión, relacionados con los entornos social-cultural, ecológico y económico.

Desde la Facultad. En esta sección se publican artículos generados en la Facultad de Diseño, relacionados con las actividades de docencia, extensión, formación en investigación o internacionalización, las cuales son reflejo de la dinámica y de las actividades realizadas por docentes, estudiantes y egresados; esta sección no puede superar el $20 \%$ del contenido.

Textos. En esta sección se publican reseñas, traducciones y memorias de eventos relacionados con las publicaciones en Arquitectura y Urbanismo.

\section{A Frecuencia de publicación}

Desde 1999 y hasta el 2015, la Revista de Arquitectura (Bogotá) publicó un volumen al año, a partir del 2016 se publicarán dos números por año en periodo anticipado, enero-junio y julio-diciembre, pero también maneja la publicación anticipada en línea de los artículos aceptados (versión Post-print del autor).

La Revista de Arquitectura (Bogotá) se divulga mediante versiones digitales (PDF, HTML, EPUB, XML) e impresascon un tiraje de 700 ejemplares, los tiempos de producción de estas versiones dependerán de los cronogramas establecidos por la editorial.

Los tiempos de recepción-revisión-aceptación pueden tardar entre seis y doce meses dependiendo del flujo editorial de cada sección y del proceso de revisión y edición adelantado.

Con el usuario y contraseña asignados, los autores pueden ingresar a la plataforma de gestión editorial y verificar el estado de revisión, edición o publicación del artículo.
A Canje

La Revista de Arquitectura (Bogotá) está interesada en establecer canje con publicaciones académicas, profesionales o científicas del área de Arquitectura y Urbanismo, como medio de reconocimiento y discusión de la producción científica en el campo de acción de la publicación.

\section{Mecanismo}

Para establecer canje por favor descargar, diligenciar y enviar el formato: RevArq FP20 Canjes

\section{Universidad Católica de Colombia (2019, enero-junio). Revista de Arquitectura (Bogotá), $2 I(\mathrm{I})$ I-120. Doi: 10.14718 \\ ISSN: 1657-0308 E-ISSN: 2357-626X \\ Especificaciones: Formato: $34 \times 24 \mathrm{~cm}$ Papel: Mate $115 \mathrm{~g}$ Tintas: Negro y policromía}

A Contacto

Dirección postal:

Avenida Caracas No. 46-72.

Universidad Católica de Colombia

Bogotá D.C.(Colombia)

Código postal: 111311

Facultad de Diseño

Centro de Investigaciones (CIFAR).

Sede El Claustro. Bloque "L", 4 piso

Diag. 46a No. 15b-10

Editor, Arq. César Eligio-Triana

Teléfonos:

+57 (1) $3277300-3277333$

Ext. $3109 ; 3112$ o 5146

Fax: +57 (1) 2858895
Correo electrónico:

revistadearquitectura@ucatolica.edu.co

cifar@ucatolica.edu.co

Página WEB:

www.ucatolica.edu.co

vínculo Revistas científicas

http://publicaciones.ucatolica.edu.co revistas-cientificas

http://editorial.ucatolica.edu.co/ojsucatolica/revistas_ucatolica/index.php/RevArq 
Universidad Católica de Colombia

Presidente

Édgar Gómez Betancourt

Vicepresidente - Rector

Francisco José Gómez Ortiz

Vicerrector Jurídico

Edwin de Jesús Horta Vásquez

Vicerrector Administrativo

Édgar Gómez Ortiz

Vicerrector Académico

Elvers Medellín Lozano

Vicerrector de Talento Humano

Ricardo López Blum

Director de Investigaciones

Edwin Daniel Durán Gaviria

Directora Editorial

Stella Valbuena García

\section{Facultad de Diseño}

Decano

Werner Gómez Benítez

Director de docencia

Jorge Gutiérrez Martínez

Directora de extensión

Mayerly Rosa Villar Lozano

Director de investigación

Hernando Verdugo Reyes

Director de gestión de calidad

Augusto Forero La Rotta

Comité asesor externo

Facultad de Diseño

Édgar Camacho Camacho

Martha Luz Salcedo Barrera

Samuel Ricardo Vélez
Facultad de Diseño

Centro de Investigaciones - CIFAR

\section{REVISTA DE ARQUITECTURA \\ Revista de Arquitectura \\ (Bogotá)}

Revista de acceso abierto,

arbitrada e indexada

Publindex: Categoría B. Índice Bibliográfico Nacional IBN.

Esci: Emerging Source Citation Index.

Doaj: Directory of Open Access Journals.

Redalyc: Red de Revistas Cientificas de América Latina y el Caribe,

España y Portugal.

SciELO: Scientific Electronic Library Online - Colombia

Redib: Red Iberoamericana de Innovación y Conocimiento Cientifico.

Ebsco: EBSCOhost Research Databases.

Clase: Base de datos bibliográfica de revistas de ciencias sociales y

humanidades.

Latindex: Sistema Regional de Información en Línea para Revistas

Científicas de América Latina, el Caribe, España y Portugal (Directorio

y catálogo).

Dialnet: Fundación Dialnet - Biblioteca de la Universidad de La Rioja.

LatinRev: Red Latinoamericana de Revistas Académicas en Ciencias

Sociales $y$ Humanidades.

Proquest: ProQuest Research Library.

Miar: Matrix for the Analysis of Journals.

Sapiens Research: Ranking de las mejores revistas colombianas según

visibilidad internacional.

Actualidad Iberoamericana: (Índice de Revistas) Centro de Información

Tecnológica (CIT).

Google Scholar

Arla: Asociación de Revistas latinoamericanas de Arquitectura.

\section{Editorial}

Av. Caracas $N^{\circ} 46-72$, piso 5

Teléfono: 3277300 Ext. 5145

editorial@ucatolica.edu.co

www.ucatolica.edu.co

http://publicaciones.ucatolica.edu.co/

Impresión:

JaVEGRAF

Calle 46A No82-54 Int. 2

Bogotá, D. C., Colombia

http://www.javegraf.com.co/index.php

Enero de 2019
Director

Werner Gómez Benítez

Editor

César Eligio-Triana

Editores de sección

(1) Myriam Stella Díaz-Osorio

(1) Carolina Rodríguez-Ahumada

(1) Anna Maria Cereghino-Fedrigo

\section{Equipo editorial}

Coordinadora editorial

María Paula Godoy Casasbuenas

mpgodoy@ucatolica.edu.co

Diseño y montaje

Juanita Isaza

juanaisaza@gmail.com

Traductoras

Inglés

Erika Tanacs

etanacs25@gmail.com

Portugués

Roanita Dalpiaz

roanitad@gmail.com

Correctora de estilo

María José Díaz Granados M.

mariajose_dgm@yahoo.com.co

Página Web

Centro de investigaciones (CIFAR)

Distribución y canjes

Claudia Álvarez Duquino

calvarez@ucatolica.edu.co
Comité editorial y científico

Cultura y espacio urbano

Carlos Mario Yory, PhD

Universidad Católica de Colombia. Bogotá, Colombia

Sonia Berjman, $\mathrm{PhD}$

ICOMOS-IFLA, Buenos Aires, Argentina

Juan Carlos Pérgolis, MSc Universidad Piloto de Colombia. Bogotá, Colombia

Beatriz García Moreno, PhD

Universidad Nacional de Colombia. Bogotá, Colombia

Proyecto arquitectónico y urbano

A Jean-Philippe Garric, PhD, HDR

Université Paris I Panthéon-Sorbonne. Paris, Francia

Debora Domingo Calabuig, PhD

Universidad Politécnica de Valencia, España

Dania González Couret, PhD

Universidad Tecnológica de La Habana, Cuba

Hugo Mondragón López, PhD Pontificia Universidad Católica de Chile. Santiago, Chile

Juan Pablo Duque Cañas, PhD

Universidad Nacional de Colombia. Bogotá, Colombia

Tecnología, medioambiente y sostenibilidad

Mariano Vázquez Espí, PhD

Universidad Politécnica de Madrid, España

Denise Helena Silva Duarte, PhD Universidade de São Paulo (USP), Brasil

Luis Carlos Herrera Sosa, PhD Universidad Autónoma de Ciudad Juárez, México

Claudio Varini, PhD

Universidad Católica de Colombia. Bogotá, Colombia

Luis Gabriel Gómez Azpeitia, PhD Universidad de Colima. Colima, México 


\section{CONTENDO}
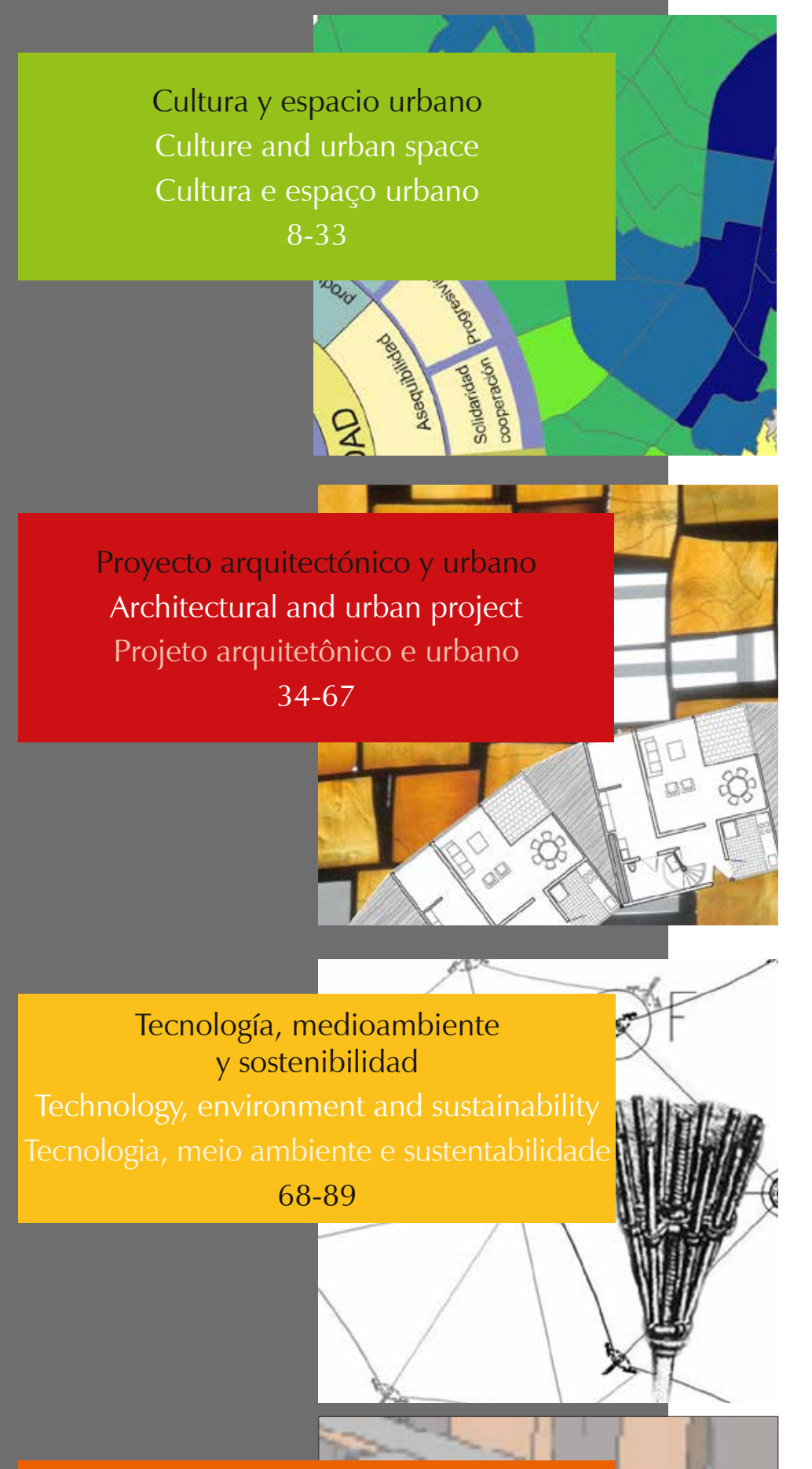

Desde la Facultad

From the Faculty

Da faculdade

90-109
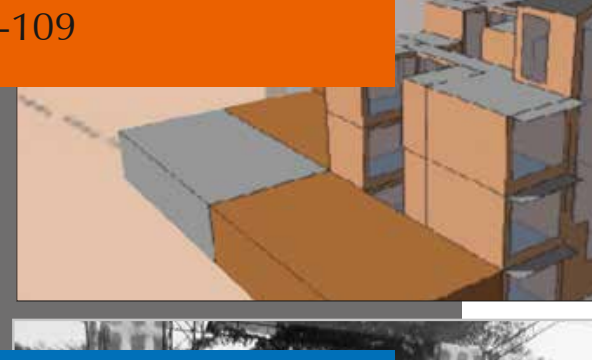

Textos

Texts

Textos

110-118
Revistas en tiempos tecno-humanos

Julio Arroyo

Pág. 3

ES

Índice de caminabilidad para la ciudad de Bogotá

Julián Alberto Gutiérrez-López
Yolanda Beatriz Caballero-Pérez
Rubén Alejandro Escamilla-Triana

ES

Pág. 8

Principios, criterios y propósitos de desarrollo sustentable para la redensificación en contextos urbanos informales
Juan José Castiblanco-Prieto
Fabián Adolfo Aguilera-Martínez
Fabián Alonso Sarmiento-Valdés

Pág. 21

ES

Complejidad y constructivismo en la nueva tradición de la arquitectura de la posguerra

Francisco Javier Fuentes-Farías

Pág. 34 ES

Conservación del arte contemporáneo

El caso de Mathias Goeritz en la Catedral

Metropolitana de México

Alberto Cedeño-Valdiviezo

Pablo Torres-Lima

Pág. 44

\section{ES EN}

Operando desde la forma: un procedimiento

para la valoración de la vivienda colectiva

Julián Camilo Valderrama-Vidal

Pág. 54

ES

Disponibilidad de las técnicas constructivas

de habitación en madera, en Brasil

Victor A. De Araujo

Carlos M. Gutiérrez-Aguilar

Juliana Cortez-Barbosa

Maristela Gava

José N. Garcia

Pág. 68

ES

Diseño y construcción de un paraguas plegable para espacios arquitectónicos

Carlos César Morales-Guzmán

Pág. 76

ES EN

Envolventes eficientes

Relación entre condiciones ambientales, espacios confortables

y simulaciones digitales

Natalia Medina-Patrón

Jonathan Escobar-Saiz

Pág. 90

ES

(Re)pensando el enfoque tecnológico:

el caso del Centro Experimental de la Vivienda

Económica (CEVE) en Argentina

Gustavo Pelegrin

Laila Fleker

Aurelio Ferrero

Pág.110 
La postulación de un artículo a la Revista de Arquitectura (Bogotá) indica que- el o los autores certifican que conocen y aceptan la política editorial, para lo cual firmarán en original y remitirán el formato RevArq FP00 Carta de originalidad.

La Revista de Arquitectura (Bogotá) maneja una política de Autoarchivo VERDE, según las directrices de SHERPA/RoMEO, por lo cual el autor puede:

- Pre-print del autor: Archivar la versión pre-print (la versión previa a la revisión por pares

- Post-print del autor: Archivar la versión post-print (la versión final posterior a la revisión por pares

- Versión de editor/PDF: Archivar la versión del editor - PDF/HTML/XLM en la maqueta de la Revista de Arquitectura (Bogotá).

El Autoarchivo se debe hacer respetando la licencia de acceso abierto, la integridad y la imagen de la Revista de Arquitectura (Bogotá), también se recomienda incluir la referencia, el vínculo electrónico y el DOI.

El autor o los autores son los titulares del Copyright (c) del texto publicado y la Editorial de la Revista de Arquitectura (Bogotá) solicita la firma de una autorización de reproducción del artículo (RevArq FP03 Autorización reproducción), la cual se acoge a la licencia CC, donde se expresa el derecho de primera publicación de la obra.

La Revista de Arquitectura (Bogotá) se guía por las normas internacionales sobre propiedad intelectual y derechos de autor, y de manera particular el artículo 58 de la Constitución Política de Colombia, la Ley 23 de 1982 y el Acuerdo 172 del 30 de septiembre de 2010 (Reglamento de propiedad intelectual de la Universidad Católica de Colombia)

Para efectos de autoría y coautoría de artículos se diferencian dos tipos: "obra en colaboración" y "obra colectiva". La primera es aquella cuya autoría corresponde a todos los participantes al ser fruto de su trabajo conjunto. En este caso, quien actúa como responsable y persona de contacto debe asegurar que quienes firman como autores han revisado y aprobado la versión final, y dan consentimiento para su divulgación. La obra colectiva es aquella en la que, aunque participan diversos colaboradores, hay un autor que toma la iniciativa la coordinación y realización de dicha obra. En estos casos, la autoría corresponderá a dicha persona (salvo pacto en contrario) y será suficiente únicamente con su autorización de divulgación.

El número de autores por artículo debe estar justificado por el tema, la complejidad y la extensión, y no deberá ser superior a la media de la disciplina, por lo cual se recomienda que no sea mayor de cinco. El orden en que se enuncien corresponderá a los aportes de cada uno a la construcción del texto, se debe evitar la autoría ficticia o regalada. Si se incluyen más personas que trabajaron en la investigación se sugiere que sea en calidad de colaboradores o como parte de los agradecimientos. La Revista de Arquitectura (Bogotá) respetará el número y el orden en que figuren en el original remitido. Si los autores consideran necesario, al final del artículo pueden incluir una breve descripción de los aportes individuales de cada uno de firmantes.

La comunicación se establece con uno de los autores, quien a su vez será el responsable de informar a los demás autores de las notificaciones emitidas por la Revista de Arquitectura (Bogotá).

En virtud de mantener el equilibro de las secciones y las mismas oportunidades para todos los participantes, un mismo autor puede postular dos o más artículos de manera simultánea; si la decisión editorial es favorable y los artículos son aceptados, su publicación se realizará en números diferentes.

\section{A Acceso abierto}

La Revista de Arquitectura (Bogotá), en su misión de divulgar la investigación y apoyar el conocimiento y la discusión en los campos de interés, proporciona acceso abierto, inmediato e irrestricto a su contenido de manera gratuita mediante la distribución de ejemplares impresos y digitales. Los interesados pueden leer, descargar, guardar, copiar y distribuir, imprimir, usar, buscar o referenciar el texto completo o parcial de los artículos o la totalidad de la Revista de Arquitectura (Bogotá).

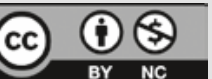

Esta revista se acoge a la licencia Creative Commons (CC BY NC de Atribución - No comercial 4.0 Internacional): "Esta licencia permite a otros entremezclar, ajustar y construir a partir de su obra con fines no comerciales, y aunque en sus nuevas creaciones deban reconocerle su autoría y no puedan ser utilizadas de manera comercial, no tienen que estar bajo una licencia con los mismos términos".

La Revista de Arquitectura es divulgada en centros y grupos de investigación, en bibliotecas y universidades, y en las principales facultades de Arquitectura mediante acceso abierto a la versión digital y suscripción anual al ejemplar impreso o por medio de canje, este último se formaliza mediante el formato RevArq FP20 Canjes

Para aumentar su visibilidad y el impacto de los artículos, se envían a bases de datos y sistemas de indexación y resumen (SIR) y, asimismo, pueden ser consultados y descargados en la página web de la revista.

La Revista de Arquitectura no maneja cobros, tarifas o tasas de publicación de artículo (Article Processing Charge-APC), o por el sometimiento de textos a la publicación.

\section{(1)Ética y buenas prácticas}

La Revista de Arquitectura se compromete a cumplir y respetar las normas éticas en todas las etapas del proceso de publicación. Los autores de los artículos publicados darán cumplimiento a los principios éticos contenidos en las diferentes declaraciones y legislaciones sobre propiedad intelectual y derechos de autor específicos del país donde se realizó la investigación. En consecuencia, los autores de los artículos postulados y aceptados para publicar, que presentan resultados de investigación, deben firmar la declaración de originalidad (formato RevArq FP00 Carta de originalidad).

La Revista de Arquitectura reconoce y adopta los principios de transparencia y buenas prácticas descritos por COPE, "Principles of Transparency and Best Practice in Scholarly Publishing" (2015).

El equipo editorial tiene la obligación de guardar la confidencialidad acerca de los artículos recibidos, y abstenerse de usar en sus propias investigaciones datos, argumentos o interpretaciones hasta tanto el artículo no sea publicado. También debe ser imparcial y gestionar los artículos de manera adecuada y en los plazos establecidos. La selección de revisores se hará con objetividad y estos deberán responder a la temática del artículo.

El editor, los autores y los revisores deben seguir las normas éticas internacionales definidas por el Committee on Publication Ethics (COPE), con el fin de evitar casos de:

- Fabricación, falsificación u omisión de datos.

- Plagio y autoplagio.

- Publicación redundante, duplicada o fragmentada.

- Omisión de referencias a las fuentes consultadas.

- Utilización de contenidos sin permiso o sin justificación.

- Apropiación individual de autoría colectiva.

- Cambios de autoría.

- Conflicto de interés (CDI) no revelado o declarado.

- Otras que pudieran surgir en el proceso de investigación y publicación. La fabricación de resultados se genera al mostrar datos inventados por los autores; la falsificación resulta cuando los datos son manipulados y cambiados a capricho de los autores; la omisión se origina cuando los autores ocultan deliberadamente un hecho o dato. El plagio se da cuando un autor presenta como ideas propias datos creados por otros. Los casos de plagio son los siguientes: copia directa de un texto sin entrecomillar o citar la fuente, modificación de algunas palabras del texto, paráfrasis y falta de agradecimientos; el autoplagio se da cuando el mismo autor reutiliza material propio que ya fue publicado, pero sin indicar la referencia al trabajo anterior. La revista se apoya en herramientas digitales que detectan cualquiera de estos casos en los artículos postulados, y es labor de los editores y revisores velar por la originalidad y fidelidad en la citación. La publicación redundante o duplicada se refiere a la copia total, parcial o alterada de un trabajo ya publicado por el mismo autor

En caso de sospechar de alguna mala conducta se recomienda seguir los diagramas de flujo elaborados por COPE (2008), con el fin de determinar las acciones correspondientes.

La Revista de Arquitectura se reserva el derecho de retractación de publicación de aquellos artículos que, posterior a su publicación, se demuestre que presentan errores de buena fe, o cometieron fraudes o malas prácticas científicas. Esta decisión se apoyará en "Retraction Guidelines" (COPE, 2009). Si el error es menor, este se podrá rectificar mediante una nota editorial de corrección o una fe de erratas. Los autores también tienen la posibilidad de solicitar la retractación de publicación cuando descubran que su trabajo presenta errores graves. En todos los casos se conservará la versión electrónica y se harán las advertencias de forma clara e inequívoca.

\section{A Privacidad y manejo de la información.} Habeas Data

Para dar cumplimiento a lo previsto en el artículo 10 del Decreto 1377 de 2013, reglamentario de la Ley 1581 de 2012, y según el Acuerdo 002 del 4 de septiembre de 2013 de la Universidad Católica de Colombia, "por el cual se aprueba el manual de políticas de tratamiento de datos personales":

La Universidad Católica de Colombia, considerada como responsable o encargada del tratamiento de datos personales, manifiesta que los datos personales de los autores, integrantes de los comités y pares revisores, se encuentran incluidos en nuestras bases de datos; por lo anterior, y en cumplimiento de las disposiciones legales vigentes, la Universidad solicitará siempre su autorización, para que en desarrollo de sus funciones propias como Institución de Educación Superior, en especial las relacionadas con la docencia, la extensión y la investigación, la Universidad Católica de Colombia pueda recolectar, recaudar, almacenar, usar, circular, suprimir, procesar, intercambiar, compilar, dar tratamiento, actualizar, transmitir o transferir a terceros países y disponer de los datos que le han suministrado y que han sido incorporados en las bases de datos de todo tipo que reposan en la Universidad.

La Universidad Católica de Colombia queda autorizada, de manera expresa e inequívoca, en los términos señalados por el Decreto 1377 de 2013, para mantener y manejar la información de nuestros colaboradores (autores, integrantes de los diferentes comités y pares revisores); así mismo, los colaboradores podrán ejercer sus derechos a conocer, actualizar, rectificar y suprimir sus datos personales, para lo cual se han dispuesto las siguientes cuentas de correo electrónico: 
La Revista de Arquitectura (Bogotá) recibe artículos de manera permanente. Los artículos se procesan a medida que se postulan, dependiendo el flujo editorial de cada sección.

El idioma principal es el español, y como opcionales están definidos el inglés, el portugués y el francés; los textos pueden ser escritos y presentados en cualquiera de estos.

Los artículos postulados deben corresponder a las categorías universalmente aceptadas como producto de investigación, ser originales e inéditos y sus contenidos responder a criterios de precisión, claridad y brevedad.

Como punto de referencia se pueden tomar las tipologías y definiciones del Îndice Bibliográfico Nacional, Publindex (2010) que se describen la continuación:

1. Artículo de revisión: documento resultado de una investigación terminada donde se analizan, sistematizan e integran los resultados de investigaciones publicadas o no publicadas, sobre un campo en ciencia o tecnología, con el fin de dar cuenta de los avances y las tendencias de desarrollo. Se caracteriza por presentar una cuidadosa revisión bibliográfica de por lo menos 50 referencias.
2. Artículo de investigación científica y tecnológica: documento que presenta, de manera detallada, los resultados originales de proyectos terminados de investigación. La estructura generalmente utilizada contiene cuatro apartes importantes: introducción, metodología, resultados y conclusiones.

3. Artículo de reflexión: documento que presenta resultados de investigación terminada desde una perspectiva analítica, interpretativa o crítica del autor, sobre un tema específico, recurriendo a fuentes originales.

Adicional a estas tipologías, se pueden presentar otro tipo de artículos asociados a procesos de investigación-creación y/o investigación proyectual. En todos los casos se debe presentar la información suficiente para que cualquier investigador pueda reproducir la investigación y confirmar o refutar las interpretaciones defendidas y sea evidente el aporte a la disciplina.

En todos los casos se debe presentar la información suficiente para que cualquier investigador pueda reproducir la investigación y confirmar o refutar las interpretaciones defendidas.

\section{(A) Instrucciones para postular artículos}

Postular el artículo en la página web de la Revista de Arquitectura (Bogotá) y adjuntar comunicación escrita dirigida al editor RevArq_FP00 Carta de originalidad (debidamente firmada por todos los autores en original); de igual manera, se debe diligenciar el formato de hoja de vida RevArq FP01 Hoja de Vida (una por cada autor).

En la comunicación escrita el autor expresa que conoce y acepta la política editorial de la Revista de Arquitectura (Bogotá), que el artículo no está postulado para publicación simultáneamente en otras revistas u órganos editoriales y que no existe conflicto de intereses (ver modelo RevArq FP06 CDI) y que, de ser aceptado, concederá permiso de primera publicación, no exclusiva a nombre de la Universidad Católica de Colombia como editora de la revista.

Los artículos deben tener en cuenta las siguientes recomendaciones:

- En la primera página del documento se debe incluir:

Tírulo: no exceder 15 palabras

Subtítulo: opcional, complementa el título o indica las principales subdivisiones del texto.

Nombre del autor o autores: nombres y apellidos completos o según modelo de citación adoptado por el autor para la normalización de los nombres del investigador. Como nota al pie (máximo 100 palabras) formación académica, experiencia profesional e investigativa, código ORCID https://orcid.org/, e información de contacto, correo electrónico.

Filiación institucional: debajo del nombre se debe declarar la ins-titución en la cual se desarrolló el producto, de la cual recibió apoyo o aquella que respalda el trabajo investigativo.

Resumen: debe ser analítico, se redacta en un solo párrafo, da cuenta del tema, el objetivo, la metodología, los resultados y las conclusiones; no debe exceder las 150 palabras.

Palabras clave: cinco palabras o grupo de palabras, ordenadas alfabéticamente y que no se encuentren en el título o subtítulo; estas sirven para clasificar temáticamente al artículo. Se recomienda emplear principalmente palabras definidas en el tesauro de la Unesco (http://databases. unesco.org/thessp/), en el tesauro de Arte \& Arquitectura (C) (www.aatespanol.cl), o Vitruvio (http://vocabularyserver.com/vitruvio/)

También se recomienda incluir título, resumen y palabras clave en segundo idioma.

- La segunda página y siguientes deben tener en cuenta:

El cuerpo del artículo se divide en: Introducción, Metodología, Resultados y Discusión de resultados; posteriormente se presentan las Conclusiones, y luego las Referencias bibliográficas y los Anexos (modelo IMRYD). Las tablas y figuras se deben incorporar en el texto.

Descripción del proyecto de investigación: en la introducción se debe describir el tipo de artículo y brevemente el marco investigativo del cual es resultado y diligenciar el formato (RevArq FP02 Info Proyectos de Investigación).

TEXTO: todas las páginas deben venir numeradas y con el título de artículo en la parte superior de la página. Márgenes de $3 \mathrm{~cm}$ por todos los lados, interlineado doble, fuente Arial o Times New Roman de 12 puntos, texto justificado (Ver plantilla para presentación de artículos). La extensión de los artículos debe ser de alrededor de 5.000 palabras ( \pm 20 páginas, incluyendo gráficos, tablas, referencias, etc.); como mínimo 3.500 y máximo 8.000 palabras. Se debe seguir el estilo vigente y recomendado en el Manual para Publicación de la American Psychological Association (APA). (Para mayor información véase http://www.apastyle.org/)
Citas y notas al pie: las notas aclaratorias o notas al pie no deben exceder cinco líneas o 40 palabras, de lo contrario estas deben ser incorporadas al texto general. Las citas pueden ser:

Corta: (con menos de 40 palabras) se incorporan al texto y pueden ser: textuales (se encierran entre dobles comillas), parafraseo o resumen (se escriben en palabras del autor dentro del texto).

Cita textual extensa: (mayor de 40 palabras) debe ser dispuesta en un renglón y un bloque independiente con sangrías y omitiendo las comillas, no olvidar en ningún caso la referencia del autor (Apellido, año, página).

Referencias: como modelo para la construcción de referencias se emplea el estilo recomendado en el Manual para Publicación de la American Psychological Association (APA) (http://www.apastyle.org/).

Siglas: en caso de emplear siglas en el texto, las figuras o las tablas, se debe proporcionar la equivalencia completa la primera vez que se empleen y encerrarlas entre paréntesis. En el caso de citar personajes reconocidos se deben colocar nombres o apellidos completos, nunca emplear abreviaturas.

Figuras y tablas: las figuras (gráficos, diagramas, ilustraciones, planos, mapas o fotografías) y las tablas deben ir numeradas y contener título o leyenda explicativa relacionada con el tema del artículo, que no exceda las 15 palabras (Figura 1. xxxxx, Tabla 1. xxxx, etc.) y la procedencia (fuente: autor o fuente, año, página). Estas se deben referenciar en el texto de forma directa o entre paréntesis; se recomienda hacerlo con referencias cruzadas.

También se deben entregar en medio digital, independiente del texto, en formatos editables o abiertos. La marcación de los archivos debe corresponder a la incluida en el texto. Según la extensión del artículo se deben incluir de 5 a 10 gráficos. Ver guía para la búsqueda de imágenes de dominio público o bajo licencias Creative Commons (CC).

El autor es el responsable de adquirir los derechos o las autorizaciones de reproducción a que haya lugar para imágenes o gráficos tomados de otras fuentes, así como de entrevistas o material generado por colaboradores diferentes a los autores; de igual manera, se debe garantizar la protección de datos e identidades para los casos que sea necesario.

FotografíA: pueden ser entregadas en original para ser digitalizadas, de lo contrario se deben digitalizar con una resolución igual o superior a 300 dpi para imágenes a color y 600 para escala de grises. Los formatos de las imágenes pueden ser TIFF, PSD o JPG, y deben cumplir con las características expresadas en el punto anterior (figuras).

Planimetría: se debe entregar la planimetría original en medio digital, en lo posible en formato CAD, y sus respectivos archivos de plumas o en PDF; de no ser posible, se deben hacer impresiones en tamaño carta con las referencias de los espacios mediante numeración y lista adjunta. Deben tener escala gráfica, escala numérica, norte, coordenadas y localización. En lo posible, no deben contener textos, achurados o tramas.

Para más detalles, consultar el documento RevArq Parámetros para Autores Descripción en el portal web de la Revista de Arquitectura (Bogotá)

\section{Beneficios}

Como reconocimiento a los autores, se les hará envío postal de dos ejemplares de la edición impresa sin ningún costo y entregada en la dirección consignada en el formato de hoja de vida (RevArq FP01); adicionalmente, se enviará el vínculo para la descarga de la versión digital.

También se enviará una constancia informativa en la que se relaciona la publicación del artículo y, de manera opcional, se pueden detallar las fechas del proceso editorial y el arbitraje realizado. 
La selección de revisores se realiza de acuerdo con los siguientes criterios:

- Afinidad temática.

- Formación académica.

- Experiencia investigativa y profesional.

- Producción editorial en revistas similares o en libros resultado de investigación.

El proceso de arbitraje se basa en los principios de equidad e imparcialidad, y en los criterios de calidad y pertinencia.

El desarrollo de la revisión se realiza según el formato (RevArq FP10 Evaluación de artículos) y las observaciones que el revisor considere necesarias en el cuerpo del artículo. En cualquiera de los conceptos que emita el revisor (Aceptar, Publicable con modificaciones, Reevaluable o No publicable), y como parte de la labor formativa y de comunidad académica, el revisor hará sugerencias para mejorar et documento. El revisor podrá solicitar una nueva relectura del artículo después de los ajustes realizados por el autor.

El revisor también deberá diligenciar el formato RevArq FP01 Hoja de Vida, con el fin de certificar y soportar el proceso de revisión ante los SIR que así lo soliciten.

En el proceso de arbitraje se emplea el método doble ciego, los nombres del revisor no serán conocidos por el autor y viceversa. Con el fin de garantizar el anonimato del autor, al artículo postulado se le han podido suprimir nombres, instituciones o imágenes que puedan ser asociadas de manera directa al autor.

Aunque se procura el anonimato, una vez recibida la invitación como par revisor del artículo, el revisor debe cerciorarse de que no exista conflicto de intereses (CDI) o alguna limitante que afecte la revisión o que pueda ser vista como tal (lazos familiares, amistad o enemistad, vínculos contractuales o laborales, posiciones éticas, etc.), de presentarse esta situación se notificara al editor. (Ver modelo RevArq FP06 CDI).

Dada la confidencialidad del proceso de revisión, y considerando los derechos de autor y de propiedad intelectual que pueda haber sobre el material que se entrega, el revisor se compromete a mantener en absoluta reserva su labor, a limitar el uso de la obra entregada solo para el propósito designado y a devolver la documentación remitida una vez concluya la actividad.

El tiempo establecido para las revisiones de pares es de máximo un mes a partir de la confirmación de la recepción de la documentación. Ese plazo podrá ser modificado de mutuo acuerdo entre e editor y el revisor, siempre y cuando no afecte la periodicidad de la revista, la impresión o el tiempo para emitir una respuesta al autor.

Los revisores se acogerán a "COPE Ethical Guidelines for Peer Reviewers" de COPE.

\section{Beneficios}

Como retribución a los revisores se les hará envío postal de un ejemplar de la edición impresa sin ningún costo y entregada en la dirección consignada en el formato de hoja de vida. También, si es de interés para el revisor, podrá hacer la solicitud de alguna de las publicaciones editadas y presentes en el catálogo de publicaciones de la UNIVERSIDAD CATÓLICA DE COLOMBIA, previa aprobación de la Editorial y sujeto a la disponibilidad.

Si lo desea tendrá derecho a una constancia de la colaboración en la revisión de artículos, la cual solo contendrá el periodo en el cual se realizó la actividad. También tendrá la posibilidad de aceptar o no la publicación de su nombre, nacionalidad y nivel máximo de formación en la página web de la Revista de Arquitectura (Bogotá) en su calidad de colaborador.

\section{A Proceso de revisión por pares}

Luego de la postulación del artículo, el editor de la Revista de Arquitectura (Bogotá) selecciona y clasifica los artículos que cumplen con los requisitos establecidos en las directrices para los autores. El editor podrá rechazar en primera instancia artículos, sin recurrir a un proceso de revisión, si los considera de baja calidad o por presentar evidencias de faltas éticas o documentación incompleta.

Los artículos se someterán a un primer dictamen del editor, de los editores de sección y del Comité Editorial, teniendo en cuenta:

- Afinidad temática, relevancia del tema y correspondencia con las secciones definidas.

- Respaldo investigativo.

- Coherencia en el desarrollo del artículo, así como una correcta redacción y ortografía.

- Relación entre las figuras y tablas con el texto del artículo.
En esta revisión se verificará el nivel de originalidad mediante el uso de software especializado (Ithenticate o similar) y recursos digitales existentes para tal fin, también se observará la coherencia y claridad en los apartados del documento (modelo IMRYD), la calidad de las fuentes y la adecuada citación, esto quedará consignado en el formato (RevArq FP09 Revisión de artículos); esta información será cargada a la plataforma de gestión editorial y estará a disposición del autor.

En caso de que el artículo requiera ajustes preliminares, será devuelto al autor antes de ser remitido a revisores. En este caso, el autor tendrá veinte días para remitir nuevamente el texto con los ajustes solicitados.

Después de la preselección se asignan mínimo dos revisores especializados, quienes emitirán su concepto utilizando el formato (RevArq FP10 Evaluación de artículos) y las anotaciones que consideren oportunas en el texto; en esta etapa se garantizará la confidencialidad y el anonimato de autores y revisores (modalidad doble ciego).

Del proceso de revisión se emite uno de los siguientes conceptos que será reportado al autor:

\section{- Aceptar el envío: con o sin observaciones.}

- Publicable con modificaciones: se podrá sugerir la forma más adecuada para una nueva presentación, el autor puede o no aceptar las observaciones según sus argumentos. Si las acepta, cuenta con quince días para realizar los ajustes pertinentes.

- Reevaluable: cumple con algunos criterios y debe ser corregido. Es necesario hacer modificaciones puntuales y estructurales al artículo. En este caso, el revisor puede aceptar o rechazar hacer una nueva lectura del artículo luego de ajustado.

- No publicable: el autor puede volver a postular el artículo e iniciar nuevamente el proceso de arbitraje, siempre y cuando se evidencien los ajustes correspondientes.

En el caso de presentarse diferencias sustanciales y contradictorias en los conceptos sobre la recomendación del revisor, el editor remitirá el artículo a un revisor más o a un miembro del Comité Editorial quien podrá actuar como tercer árbitro, con el fin de tomar una decisión editorial sobre la publicación del artículo.

Los autores deberán considerar las observaciones de los revisores o de los editores, y cada corrección incorporada u omitida debe quedar justificada en el texto o en una comunicación adjunta. En el caso que los autores omitan las indicaciones realizadas sin una argumentación adecuada, el artículo será devuelto y no se dará por recibido hasta que no exista claridad al respecto.

El editor respetará la independencia intelectual de los autores y a estos se les brindará el derecho de réplica en caso de que los artículos hayan sido evaluados negativamente y rechazados.

Los autores, con su usuario y contraseña, podrán ingresar a la plataforma de Gestión Editorial, donde encontrarán los conceptos emitidos y la decisición sobre el artículo.

El editor y el Comité Editorial se reservan el derecho de aceptar o no la publicación del material recibido. También se reservan el derecho de sugerir modificaciones de forma, ajustar las palabras clave o el resumen y de realizar la corrección de estilo. El autor conocerá la versión final del texto antes de la publicación oficial del mismo.

Cuando un artículo es aceptado para su publicación, el autor debe firmar la autorización de reproducción (RevArq FP03 Autorización reproducción). Para más información ver: Política de derechos de autor

\section{Notas aclaratorias:}

La Revista de Arquitectura (Bogotá) busca el equilibrio entre las secciones, motivo por el cual, aunque un artículo sea aceptado o continúe en proceso de revisión, podrá quedar aplazado para ser publicado en un próximo número; en este caso, el autor estará en la posibilidad de retirar la postulación del artículo o de incluirlo en el banco de artículos del próximo número.

El editor y los editores de sección de la Revista de Arquitectura (Bogotá) son los encargados de establecer contacto entre los autores y revisores, ya que estos procesos se realizan de manera anónima.
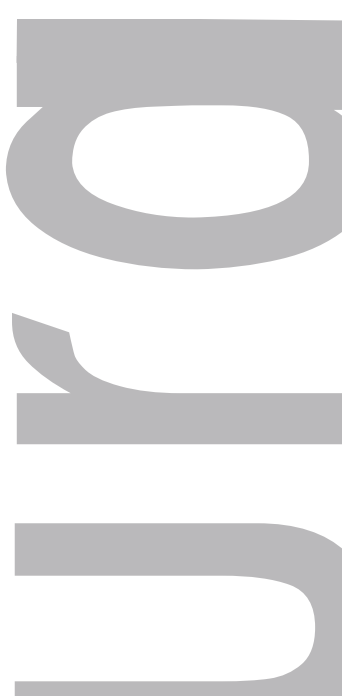
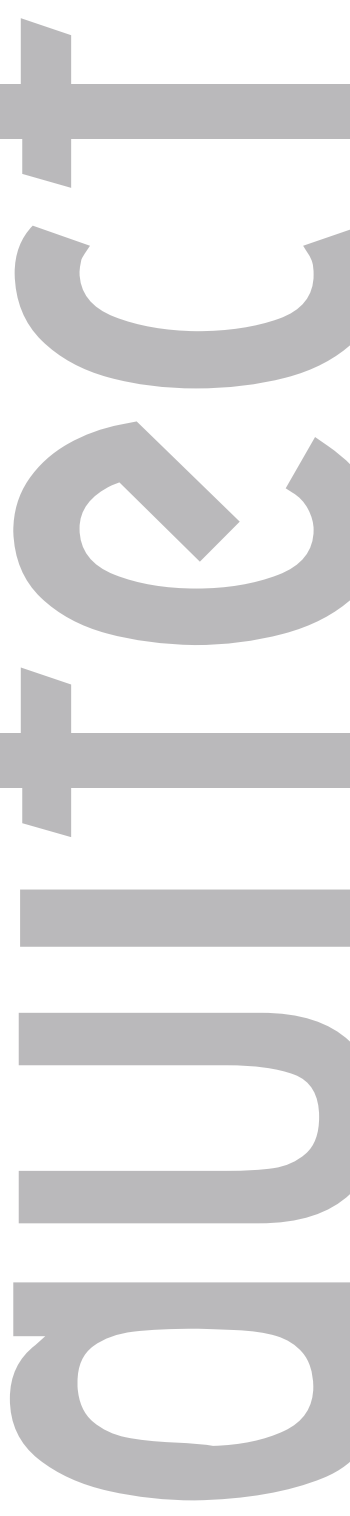

Vol. 
Índice de caminabilidad para la ciudad de Bogotá

$\infty \quad$ Walkability index for the city of Bogotá

ن Índice de caminhabilidade para a cidade de Bogotá

¿ Julián Alberto Gutiérrez-López

Yolanda Beatriz Caballero-Pérez

Rubén Alejandro Escamilla-Triana

Principios, criterios y propósitos de desarrollo sustentable para la $\bar{\sim}$ redensificación en contextos urbanos informales

$\sim$ Principles, criteria and purposes of sustainable development for

re-densification in unplanned urban contexts

Princípios, critérios e propósitos de desenvolvimento sustent

luan José Castiblanco-Prieto

Fabián Adolfo Aguilera-Martínez

Fabián Alonso Sarmiento-Valdés

Complejidad y constructivismo en la nueva tradición de la arquitectura de la posguerra

Complexity and constructivism in the new tradition of post-war architecture

U. Complexidade e construtivismo na nova tradição da arquitetura do pósguerra

Francisco Javier Fuentes-Farías

Conservación del arte contemporáneo. El caso de Mathias Goeritz en la Catedral Metropolitana de México

Conservation of contemporary art: The case of Mathias Goeritz in the

ن் Metropolitan Cathedral of Mexico

$₫ \quad$ Conservação da arte contemporânea: o caso de Mathias Goeritz na Catedral Metropolitana do México

\section{Alberto Cedeño-Valdiviezo}

Pablo Torres-Lima

Operando desde la forma: un procedimiento para la valoración de la vivienda colectiva

เก Operating based on form: A procedure for the valuation of collective housing

ن Operando a partir da forma: um procedimento para avaliar a moradia coletiva

\section{^ Julián Camilo Valderrama-Vidal}

Disponibilidad de las técnicas constructivas de habitación en madera, en Brasil

ن Availability of timber housing construction techniques in Brazil

Disonibilidade das técnicas construtivas de moradia em madeira no Brasil

\section{Victor A. De Araujo}

Carlos M. Gutiérrez-Aguilar

luliana Cortez-Barbosa

Maristela Gava

losé N. Garcia

Diseño y construcción de un paraguas plegable

* para espacios arquitectónicos

Design and construction of a folding umbrella for architectural spaces

Uั Desenho e construção de um guarda-chuva dobrável para espaços arquitetônicos

Carlos César Morales-Guzmán

Envolventes eficientes. Relación entre condiciones ambientales, espacios confortables y simulaciones digitales

Efficient building envelopes: Relationship between environmental conditions,

U. comfortable spaces, and digital simulations

Envolventes eficientes: relação entre condições ambientais, espaços confortáveis e simulações digitais

Natalia Medina-Patrón

Jonathan Escobar-Saiz

(Re)pensando el enfoque tecnológico: el caso del Centro

Experimental de la Vivienda Económica (CEVE) en Argentina

ㅇ (Re)thinking the technological approach: The case of the Experimental Center

으 for Economic Housing (CEVE) in Argentina

ن (Re)pensando a abordagem tecnológica. O caso do Centro Experimental da

Moradia Econômica na Argentina

Gustavo Pelegrin

Laila Fleker

Aurelio Ferrero 